\title{
Oblique evaporation and surface diffusion
}

\author{
Leon Abelmann *, Cock Lodder \\ MESA Research Institute, University of Twente, P.O. Box 217, 7500 AE Enschede, Netherlands
}

\begin{abstract}
The special structure of obliquely evaporated films has its origin in shadowing phenomena during film growth. Because of shadowing, the film consists of bundles of inclined columns with the bundles being aligned perpendicularly to the vapour incidence direction. The column inclination angle lies between the film normal and the vapour incidence direction. Different models found in literature relating process parameters and film structure are discussed. It is found that surface diffusion plays an important role, especially with regard to the difference between random and directional surface diffusion. The latter is induced by the oblique evaporation process. A quantitative expression is given for the relation between process conditions and surface diffusion including the influence of substrate temperature, rate and contamination with residual gasses. Using these models and adding our new calculations, the relation between surface diffusion and film structure is discussed in detail and found to be consistent with measurements published in the literature. (C) 1997 Elsevier Science S.A.
\end{abstract}

Keywords: Surface diffusion; Oblique evaporation

\section{Introduction}

The discovery that the oblique incidence of vapour atoms during evaporation drastically changes the film properties was made simultaneously by Knorr and Hoffmann [1] and Smith [2]. The discovery by Smith was made during the evaporation of permalloy on rather large substrates ( 3 in. $^{2}$, Fig. 1). The direction and magnitude of magnetic anisotropy were influenced by the deposition geometry. This became very clear when the substrate was tilted through an angle of $45^{\circ}$. One year later, Smith et al. concluded that the origin must be shadowing: "the area behind a crystallite is left vacant because it is in the crystallite's shadow" [3]. This phenomenon was not unknown. It had been exploited for years in electron microscopy to enhance the contrast of weakly reflecting surfaces and to emphasise the surface roughness by decoration [4].

In the following years this shadowing effect proved to be a very suitable way to enhance anisotropy and coercivity in magnetic thin films when high substrate temperatures cannot be used. The effect was finally commercialised 30 years later when Metal Evaporated video tape [5] was introduced onto the market.

\footnotetext{
${ }^{*}$ Corresponding author.
}

Obliquely evaporated films do not only show a magnetic anisotropy [6], but the special morphology of the films also induces anisotropy in other macroscopic properties. The electrical resistance of obliquely evaporated films is higher in the direction parallel to the projection of the vapour incidence direction onto the film surface [7]. We have measured differences in specific resistance as high as $150 \%$ [8]. Because of the special morphology, the stress in these films is also anisotropic [9].

Similarly, the optical properties are anisotropic [10] causing polarisation of reflected and transmitted lightwaves. Maximum transmission of light occurs when the incident light beam is parallel to the inclined columnar direction, an effect which might find its application in automotive windscreens which block out sunlight, but ensure visibility on the road [11].

In this paper, first, an overview will be given of models of oblique evaporation published in literature (Section 2). From this overview, the obvious conclusion can be made that surface diffusion is very important, like it is for all thin film growth processes. Of all models listed, the model suggested by Hara et al. is the only one that includes the effect of conservation of parallel momentum. The basis of this model is that the momentum of the incident vapour atoms parallel to the film plane causes a deviation of the columnar inclination from the vapour incidence direction toward the film surface. Hara et al. argue that, with increasing surface diffusion, this effect becomes less im- 


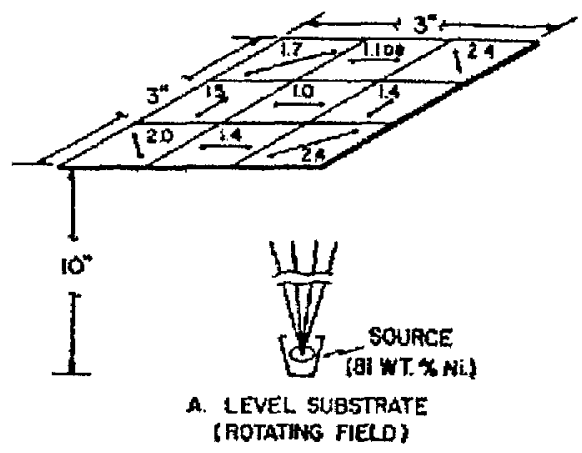

Fig. 1. Observation made by Smith [2] that the magnetic easy axis in Permalloy depended on system geometry.

portant and the columnar inclination rotates back toward the vapour incidence direction. In this model, the columnar inclination should therefore depend strongly on the surface diffusion. Therefore, a detailed quantitative investigation of the effect of process parameters on surface diffusion is given (Section 3). Our calculations on surface diffusion are tested on measurements of columnar inclination published in literature (Section 4). It is concluded that the Hara model does seem to be approximately correct and that at least qualitative predictions are possible.

\section{Models published in literature}

Since its discovery in 1959, the oblique incidence effect has been the subject of many papers that tried to explain the observed phenomena. In this section, a survey is given of models treating the special film structure of obliquely deposited thin films.

\subsection{Models for morphology}

Experiments show that films deposited under an oblique angle of vapour incidence and at a moderate substrate temperature (for $\mathrm{Co}, \mathrm{Ni}$ and $\mathrm{Fe}$ below $700 \mathrm{~K}$ ) show a columnar morphology. The columns are inclined from the substrate normal toward the vapour incidence direction. Several models have been published on the relation between the columnar inclination angle $(\beta)$ and the angle of vapour incidence ( $\alpha$ ) (Fig. 2). The columnar separation is

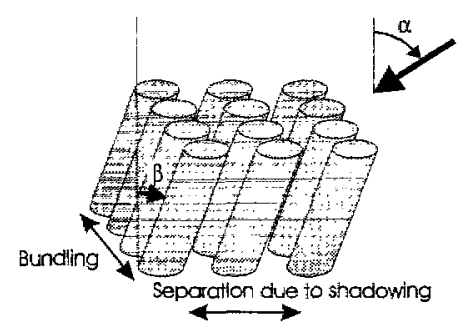

Fig. 2. Vapour incidence direction $\alpha$, columnar inclination $\beta$, bundling and cross-sectional shape. larger in the plane given by the vapour incidence direction and the substrate normal (the vapour incidence plane) than in the direction perpendicular to it. This leads to what is called "bundling" of columns. The shape of the cross-section of the columns made perpendicular to their axis is elliptic, with the long axis of the ellipse either perpendicular or parallel to the vapour incidence plane. In the following models on columnar inclination, bundling and crosssectional shape will be discussed.

\subsubsection{Column angle}

Seventeen years after the discovery of the shadowing effect, Dirks and Learny [12] of Philips published an overview paper which has been of major importance. They tried to calculate the relation between columnar inclination and the vapour incidence direction by a quasi continuum approach and by computer ballistic simulations. These two methods have been pursued further and more explanations have been proposed by other authors.

For the inclination of the columns from the vapour incidence direction toward the substrate normal, four explanations have been found in literature:

1. Adaptation of the continuum model for finite atomic size

2. Shadowing (Ballistic simulation software)

3. Conservation of parallel momentum

4. Angle dependent growth

2.1.1.1. Discretisation continutum model. Earlier measurements [13] indicated that $\alpha$ and $\beta$ were approximately related by $\tan (\beta)=1 / 2 \tan (\alpha)$, often referred to as the tangent rule. Assume a surface irregularity (e.g., edge of a nucleus) as in Fig. 3.

In a continuum growth model, the edge of the layer would grow exactly toward the source. Dirks and Leamy [12] argue that the continuum approach is too simple because one should include the finite atom size. In fact, the film grows layer by layer, and a layer cannot terminate as in Fig. 3. Therefore they state that "the mean location of the position where the layer terminates is therefore that for which the continuum model thickness is one half'. This is indicated in Fig. 4 in the inset by $1 / 2 h$. Indeed one can then simply derive the tangent rule. The reason why $1 / 2 h$ is chosen is unclear. Dirks and Leamy recognised this as
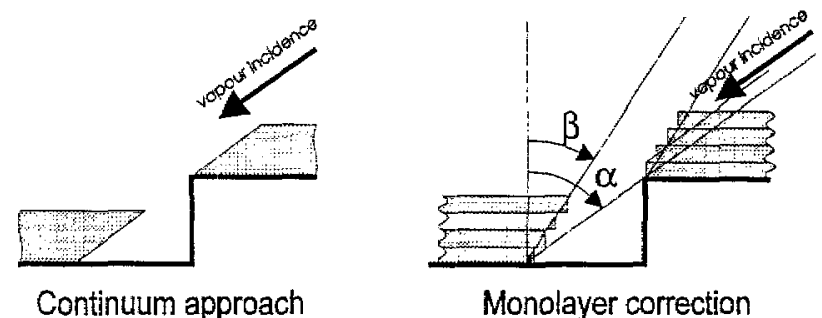

Monolayer correction

Fig. 3. Derivation of the tangent rule. Left: continuum approach. Right: modification for finite size of atoms. 


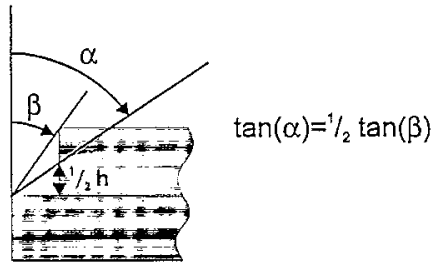

Fig. 4. Derivation of the tangent rule. The mean location of the position where the layer terminates is that for which the continuum model thickness is one half.

well and withdrew their theory in 1980: "In reality, atoms are even attached at the step edge to produce overhanging configurations, i.e., one for which $\beta<0$ " [14]. Due to its simplicity, the tangent rule nowadays is still used, even though large deviations are observed. It is good to state that this zule does not have any physical meaning, it is merely a description which seems to fit a number of measurements.

2.1.1.2. Self-shadowing, ballistic simulation software. In the same paper, Dirks and Leamy [12] present a second model relating $\alpha$ and $\beta$. Because of oblique incidence, atoms will be shadowed by neighbouring atoms. As a result, the average pair orientation will shift from the vapour incidence direction toward the film normal (Fig. 5). The mean pair orientation will depend on the average distance between the atoms and their relative vertical position.

The effect of shadowing is studied by using computer simulations. Ballistic simulation software with different levels of complexity can be found. One uses lattices where the atoms can only occupy fixed points in space. These models have the advantage that a large number of atoms can be used $\left(10^{10}[15]\right)$, but they are not very realistic since the type of lattice used influences the result (For example the square lattice used by Krug and Meakin [16]).

In off-lattice simulations, fewer particles $\left(10^{7}\right)$ can be taken into account, but they show more realistic morphology. Both 2D [14] and 3D simulations [17,15] can be found. However, these large scale models do not represent the surface diffusion of the adatoms. When one takes

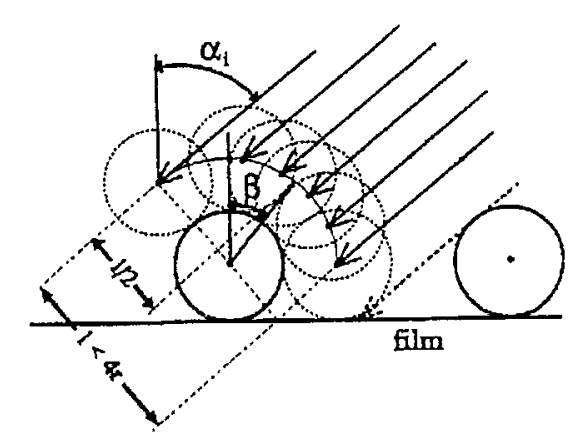

Fig. 5. Shadowing caused by neighbouring atoms will shift the mean pair orientation toward the substrate normal [12].

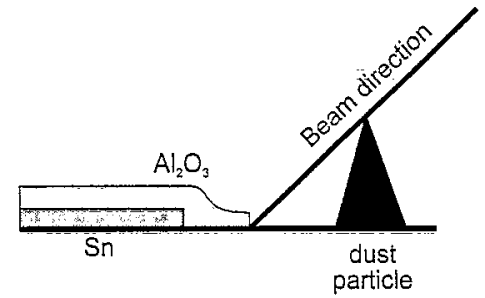

Fig. 6. Experimental proof of conservation of parallel momentum [20].

surface diffusion into account again, the number of particles must be reduced. Müller-Pfeiffer et al. [18] has included surface diffusion in a model of $5 \cdot 10^{5}$ particles. It was found that with increasing surface diffusion, the columns tilted more slightly toward the film normal (See also [19]). The model includes the conservation of parallel momentum, which is discussed next, only to decide which absorption-site an arriving atom will choose, in case of -doubt. Ballistic simulation software, including the effect of conservation of parallel momentum over larger distances, has not been found.

2.1.1.3. Conservation parallel momentum. Van de Waterbeemd and Oosterhout [20] shadowed dust particles on an amorphous Carbon substrate subsequently with $\mathrm{Sn}$ and $\mathrm{Al}_{2} \mathrm{O}_{3}$ and proved that the $\mathrm{Sn}$ adatoms migrate parallel to the incident vapour beam (Fig. 6). Upon impact, the adatoms keep a part of their momentum parallel to the substrate surface. This conservation of parallel momentum has already been used in 1937 by Lennard-Jones [21,22] to explain the anomalous diffraction of Helium by certain crystals. Kamberský et al. [23] suggested that it might play a decisive role in the formation of the film structure under oblique vapour incidence.

When adatoms arrive at the top of the column, it is possible that they will also continue to move for a short distance in the direction defined by the vapour beam causing the column to tilt from the vapour incidence direction toward the substrate normal (Fig. 7). This effect will only be visible if the random surface diffusion after relaxation is negligible. One should therefore make a distinction between directional and random surface diffusion. This line of reasoning has been used in a series of papers (at least 31) published by a group of Japanese

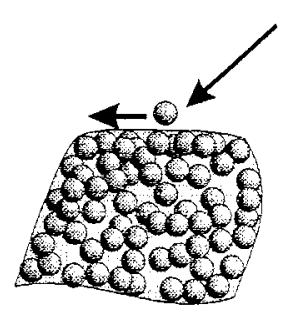

Fig. 7. Conservation of parallel momentum causes the column to tilt from the vapour incidence direction toward the substrate normal [24]. 
researchers, starting in 1970 by a Ph.D. study of Kazuhiro Hara [7]. Hara et al. [24] summarise their theory in 1988:

"An active surface diffusion points the column axis to the vapour beam direction and makes the dense-packed columnar structure. On the other hand, the movement due to momenta deviates the column axis from the vapour beam direction toward the film normal and forms a bundle of columnar grains along the direction perpendicular to the incidence plane'".

The model remains qualitative, no attempts have been made to calculate the value of directional or random surface diffusion. It should be noted that the effect depends on the slope of the top of the column which is not always parallel to the substrate surface.

\subsubsection{Angle dependent growth, continulum approach.} The columnar diameter is much larger than the atom diameter. A continuum model could therefore prove its use. In a continuum model, the finite size of the atoms is not taken into account, the surface of the film is merely described by a continuous function of the coordinates along the substrate surface and the deposition time.

One generaliy starts with a substrate with an initial roughness (Fig. 8) described by its height $h(x)$. The growth rate depends on the slope of the surface $\mathrm{d} h / \mathrm{d} x$. By tracing the top of an initial disturbance, a kind of column angle is obtained [25].

By taking different functions relating growth rate to surface slope, one can take surface diffusion and even shadowing into account. Lichter and Chen [25] include surface diffusion, but their model only allows for small surface slopes and ignores shadowing. They conclude that, with increasing random surface diffusion and increasing initial surface roughness, the columns grow more toward the vapour beam. Bindell and Tisone [26] introduce shadowing for step coverage calculations. In their model, computer simulations are necessary to determine whether or not a part is shadowed. Their model does not deal with columnar growth, neither does the model of Bales and Zangwill [27], but it includes diffusion as well as shadowing.

The continuum analysis strongly depends on the choice

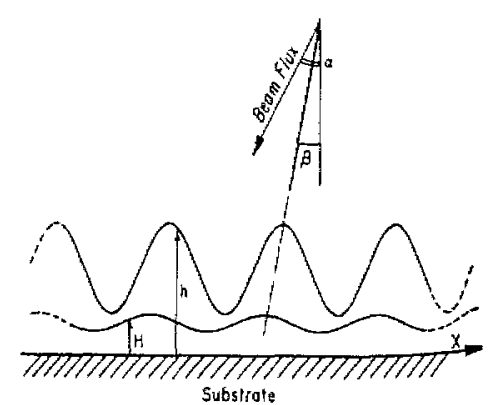

Fig. 8. Continuum approach: the calculated columnar inclination [25].
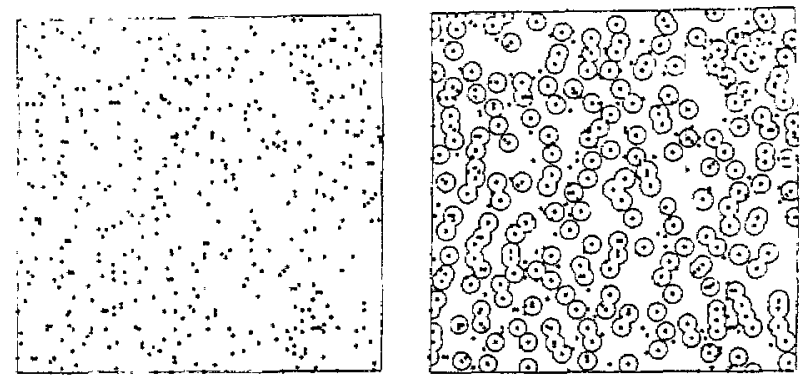

Fig. 9. Schematic illustration of the self-shadowing process at an incidence angle of $60^{\circ}$. The vapour incidence is from the right. Left: random nucleation. Right: formation of vertical chains (top to bottom) [3].

of the growth function and the choice of the initial surface perturbation. No analysis of the combination of oblique evaporation and shadowing was found. It might well be that a continuum model including oblique vapour incidence, shadowing and surface diffusion becomes so complex that a ballistic approach as previously mentioned is more straightforward.

\subsubsection{Bundling}

The effect of bundling was observed by electron microscopy immediately after the effect of oblique incidence was discovered [3]. Self-shadowing was held responsible for the bundling. The term self-shadowing is introduced to discriminate shadowing caused by other nuclei from shadowing caused by surface roughness or dust particles. The layer growth will start with a random distribution of nuclei which will act as locations for further growth (Fig. 9). Once a nucleus is formed, it will cast a shadow. When nuclei grow, they will leave emply areas behind them which cannot be filled by secondary nucleation. The nuclei coalesce into chains with the long axis of the chain running perpendicular to the vapour incidence plane. This argument is also used by Dirks and Leamy [14,28].

The argument of conservation of parallel momentum is used by Hara et al. to explain bundling. Two versions have been formulated. Fujiwara et al. [29] state

"When the normal of the top surface of the columnar grain is not parallel to the incidence plane, the adatoms move also in the direction perpendicular to the incidence plane. Such a movement induces the bundling of columnar grains."

This effect will certainly occur. The question, however, is how far the impinging atoms will move due to the conservation of momentum. Probably the effect of conservation of momentum on bundling is much smaller than the effect of self-shadowing.

According to Hara et al. [30], it is not necessary to have the normal of the top surface of the column parallel to the incidence plane:

"After arriving around the edge of the surface, the adatoms move along this edge and induce elongation of the grain 
oxygen/metal ratio
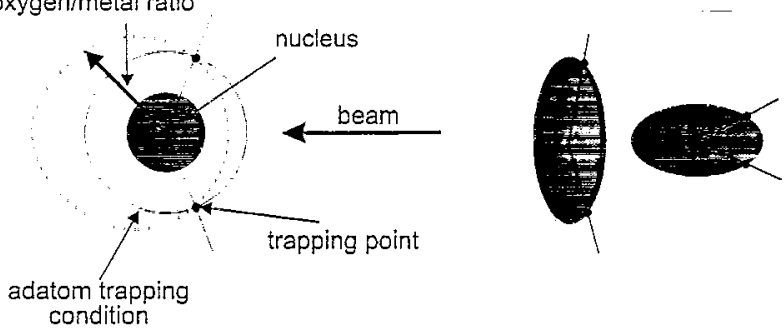

Fig. 10. Left: on the right side of the nucleus, which is exposed to the vapour beam, the relative oxygen concentration is low as indicated by the dotted line. Adatoms arriving at the nucleus will travel along its contour until the relative oxygen concentration passes a critical value (trapping point) and they are trapped. Right and middle: dependent on the position of the trapping point, the nucleus can be elongated either perpendicular or parallel to the vapour incidence direction.

perpendicular to the incidence plane or create nuclei for new columnar grains. Successive adatom movements along the edge form a bundle of columnar grains."

This argument is debatable, it is unclear why the atoms would move around the edge. The conservation of parallel momentum is not needed for the explanation of bundling. Probably, the effect of self-shadowing is dominant and is therefore preferred.

\subsubsection{Cross-sectional shape}

The conservation of parallel momentum plays a role in determining the shape of the nuclei. Van de Waterbeemd and Oosterhout [20] state that the combination of the conservation of parallel momentum and oxygen causes elongation of the nuclei. The nuclei can either be elongated parallel or perpendicular to the vapour incidence plane.

Consider a vapour atom arriving on the substrate. Due to conservation of parallel momentum, it will continue travelling in the direction given by the projection of the vapour beam direction onto the substrate. If it encounters a nucleus, it will travel along its contour and get trapped at some point. This point is strongly determined by the relative oxygen concentration, the ratio between the number of oxygen molecules and adatoms. This relative oxygen concentration varies along the nucleus contour due to the combination of anisotropic supply of adatoms and isotropic supply of oxygen atoms from the background gas. At the beam-side of the nucleus (Fig. 10), the relative oxygen concentration is minimal because the adatom supply is maximal. At the shadow side of the nucleus, the relative oxygen concentration is maximal. At a critical relative oxygen concentration, the adatoms will be trapped. In the figure, the metal:oxygen ratio is indicated by a dotted line while the critical ratio is indicated by the solid line. The adatom trapping point will be at the crossing points of the two lines. Dependent on the position of the trapping points, the nucleus can become elongated either parallel or perpendicular to the vapour incidence direction (Fig. 10 right).

Whether the ellipticity of the nuclei will result in columns with elliptic cross-sectional shapes depends on the further coalescence and growth processes.

\subsection{Models for texture}

Even before the angle-of-incidence effect was discovered, the influence of the angle of incidence on the crystal structure had been investigated [31]. It was shown that the crystal's main axes change their direction with the changing angle of incidence and other deposition parameters. Textures can be characterised by their degrees of freedom lost [32]. In the case of epitaxy, all three degrees of freedom are lost. In polycrystalline films deposited under normal vapour incidence, usually two degrees of freedom are lost ([100] direction perpendicular to the substrate, for instance. In that case the [010] direction, which lies inplane, can be chosen in any direction).

At normal vapour incidence, there is only one reference plane, the substrate. However, at oblique incidence the vapour incidence plane also forms a reference plane. Both the orientation of the crystal with respect to the substrate surface and the orientation with respect to the vapour incidence plane are important. As a result, textures with three degrees of freedom lost can be found in obliquely evaporated films.

The texture in oblique deposited films has to be defined by two crystallographic directions. A common method is to use brackets and parentheses, as in [100](010) for a cubic crystal, for example. The square brackets indicate
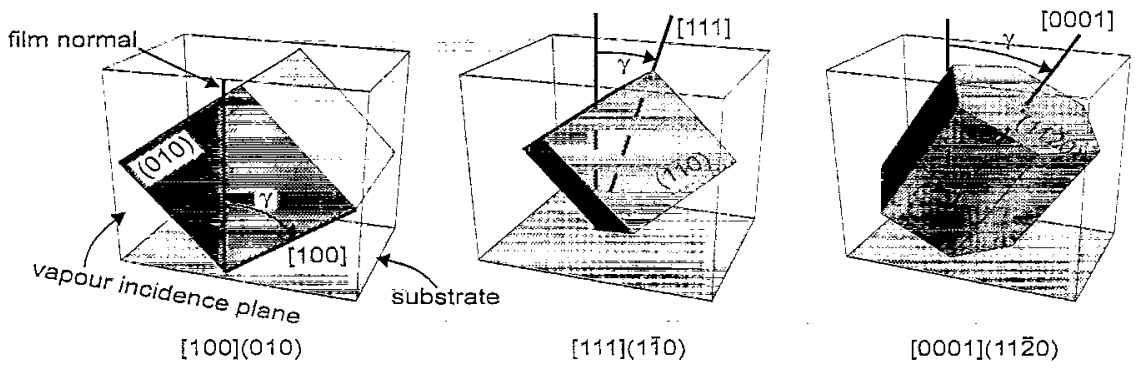

Fig. 11. Orientations often found in obliquely deposited films with cubic (left and middle) and hexagonal (right) crystal structures. 
the crystallographic direction, and the parentheses the crystal plane parallel to the vapour incidence plane [e.g. [33]].

In Fig. 11, some examples are given. The box with solid sides represents the crystal unit cell of the respective crystal cell. In $\mathrm{Fe}$ and $\mathrm{Ni}$, which have a cubic structure, $[100](010)$ or $[111](1 \overline{1} 0)$ orientations are often found. In hexagonal materials like $\mathrm{Co},[0001](11 \overline{2} 0)$ is commonly observed.

Models presented in literature relating to the texture axis inclination to the angle of vapour incidence agree that certain crystal planes are favoured in growth over others. Bauer [34] states that initially the crystals will try to grow in such a way that they minimize their free surface energy. The crystals will only succeed in obtaining this equilibrium orientation if the rate of supply of atoms to all crystal planes is uniform, which is only the case if the surface diffusion is high or if the vapour atoms arrive from all sides. The surface free energies of the crystal planes can be changed by adsorption of gasses, resulting in a different equilibrium orientation.

If surface diffusion decreases, the growth rate of crystal planes will become dependent on the local angle of vapour incidence. Bauer defines the condensation coefficient as the fraction of the impinging atoms that finally contribute to the film growth. The condensation coefficient can be less than unity because the impinging atoms bounce back from the film surface or because they re-evaporate before being incorporated in the film. According to Bauer, the condensation coefficient is dependent on the angle between the vapour incidence and the normal to the crystal plane and the angle between the projection of the vapour incidence direction on the crystal plane and the direction of densest packing in the surface. The angle dependency of the condensation coefficient is also changed by the temperature of the crystal, the rate of evaporation, the background pressure, the type of crystal plane and perhaps more variables.

Van der Drift [32] points out that not only does the condensation coefficient govern the growth rate of certain crystal planes, it also simplifies their vertical growth rate (with respect to the substrate). For $\mathrm{Fe}$ and $\mathrm{Ni}$, the fastest growth rate is the [111] direction, whereas for $\mathrm{Co}$, it is the [0001] direction. Crystals which have the fastest growth direction perpendicular to the substrate will outgrow other crystals under a uniform supply of atoms. This mechanism of survival of the fastest is called evolutionary selection by van der Drift. In this respect, he disagrees with Bauer's explanation of equilibrium growth under isotropic supply.

Van der Drift discusses four regimes of surface diffusion:

I. If the surface diffusion is practically infinite and atoms can travel from crystal to crystal (directly or over the substrate), the crystals with the fastest growing direction perpendicular to the substrate will survive.

II. If the surface diffusion is quasi-infinite but limited to the individual crystals, the direction of fastest vertical growth depends on the condensation coefficient. If the condensation coefficient is independent on the angle of incidence, the angle of the texture axis is given by:

$\gamma=\frac{1}{2} \alpha-45^{\circ}\left[{ }^{\circ}\right]$

At normal incidence ( $\alpha=0$ ), the orientations in Fig. 11, for instance, have a texture inclination of about $45^{\circ}$ according to this equation.

MI. If the surface diffusion is quasi-infinite but restricted to the crystal planes, the growth orientation is very dependent on the condensation coefficient. In the case of cubic crystals and a condensation coefficient independent of $\alpha$, the relation $\gamma=1 / 2 \alpha$ is found.

IV. If there is no surface diffusion, the typical crystal shape is lost. Preferential growth can develop only if the condensation coefficient is angle dependent.

If the surface diffusion is limited, an intermediate case is obtained and calculations become complex. It is, however, useful to regard the extreme cases listed above.

Hergt and Pfeiffer [35] add to van der Drift's theory the mechanism of conservation of parallel momentum but do not discuss any results.

\subsection{Discussion of models}

The material properties of obliquely deposited films strongly depend on the columnar separation. This separation increases with increasing angle between the columnar inclination direction and the vapour incidence direction ( $\alpha$ and $\beta$ in Fig. 2). In thin film growth processes, surface diffusion strongly influences the final morphology and texture of the film. In the case of oblique deposition, the surface diffusion will therefore affect the columnar inclination angle and separation. A correct model for oblique evaporation must therefore include the effect of surface diffusion. The continuum approach of Lichter and Chen [25] and the conservation of parallel momentum model of Hara et al. [24] both predict an increase of columnar inclination angle $\beta$ with increasing surface diffusion. The ballistic simulations of Müller-Pfeiffer and Kranenburg [18] predict only a slight decrease with increasing surface diffusion. Measurements of the columnar inclination as a function of changes in process parameters, as discussed in Section 4, clearly support the prediction of the first two models.

\subsubsection{Parallel momentum}

Hara's model is based on the effect of conservation parallel momentum, whereas the Lichter and Chen model is not. The van de Waterbeemd and Oosterhout experiment with subsequent oblique evaporation of $\mathrm{Sn}$ and $\mathrm{Al}$ in an $\mathrm{O}_{2}$ atmosphere [20] seem to indicate that conservation of parallel momentum is a factor which should be accounted for in oblique evaporation. One should keep in mind, though, that in their experiment they investigate the sur- 
face diffusion of adatoms on a surface of a different material, glass and Sn, respectively. The theories discussed in this paper deal with the situation of growth on a surface of the same material, i.e., Co on a Co surface, so there is no difference between the adatom and surface atom mass and the binding energy of Co on a Co surface is probably higher than that for $\mathrm{Sn}$ on a glass surface. The quiestion therefore remains whether the conservation of parallel momentum induces directional surface mobility.

Recently this question has been the subject of molecular dynamics studies in a quite different context. Reflection high energy electron diffraction (RHEED) observations during expitaxial growth of, for instance, $\mathrm{Fe}$ on $\mathrm{Ag}$ (100) at $77 \mathrm{~K}$ seem to indicate that film growth proceeds by a layer-by-layer mode [36]. For this type of layer growth, a considerable amount of surface diffusion is necessary so that adatoms deposited on top of an island can migrate to the edge. Since at this substrate temperature thermally activated diffusion of adatoms is negligible, there must be another mechanism causing the adatom mobility. Several theories have been proposed [37], among them is the effect of oblique incidence. Molecular dynamics simulations however show that when the atoms approach the film surface, their trajectories are strongly deflected; the actual direction of impact at the film surface is nearly perpendicular and almost independent of the initial angle of incidence [38]. This is caused by the relatively low kinetic energy of the impinging atoms (approximately $0.2 \cdot 10^{-19}$ $\mathrm{J}$, see Fig. 16) as compared to the energy they acquire upon condensation (about $7 \cdot 10^{-19} \mathrm{~J}$, see Table 1). One might argue that although the condensation energy is very high, the parallel component of the kinetic energy is still preserved and directional mobility might occur. Molecular dynamic simulations of oblique deposition of $\mathrm{Cu}$ on a $\mathrm{Cu}$ (111) surface at $80 \mathrm{~K}$, however, do not show any significant enhancement of mobility.

Three remarks can be made on the aforementioned molecular dynamics simulations. In the first place, all calculations were performed at very low substrate temperatures. To our knowledge, no molecular dynamic studies involving oblique incidence on surfaces at room temperature have been performed. It is possible that at higher substrate temperatures, oblique incidence does cause directional mobility. An indication for this might be that for $\mathrm{Ag}$ on a $\mathrm{Ag}$ surface, where the diffusion barrier is relatively low, some transient mobility has been found.

Secondly, these studies try to explain layer-by-layer growth, for which surface diffusion over several lattice sites is necessary. In the case of oblique evaporation and columnar growth, the directional diffusion would not have to be as large to cause a deviation between the columnar growth direction and the vapour incidence direction. A directional mobility of one lattice site per incident atom would already cause a huge deviation.

And finally one can make the observation that even though the impinging atom does not show directional mobility, the parallel momentum in combination with the sudden release of condensation energy might cause already deposited atoms to migrate in the direction of the parallel momentum. The activation of mobility of existing adatoms is supported by molecular dynamics simulations $[41,59]$.

Assuming that the effect of parallel momentum exists, then the argument Hara uses to explain the increase in columnar inclination with increasing surface diffusion is still debatable. Even if the distance the adatoms travel due to random surface diffusion is much larger than the distance they travel due to conservation of parallel momentum, the effect of parallel momentum will still be there and the average location of the adatoms will shift from the impingement spot. The ratio between the directional movement of adatoms due to the conservation of parallel momentum and the random movement will decrease with increasing surface diffusion, which might cause the increase in columnar inclination $\beta$. However, Hara does not indicate a mechanism for this.

In general, the observation that an increase in surface diffusion tilts the columnar inclination toward the vapour incidence direction is also in contradiction with the intuitive argument that if the surface diffusion becomes very large the adatoms "forget" were they came from and the difference between oblique incidence and normal incidence disappears.

Whether or not Hara's model is physically correct, in first approximation, an increase in surface diffusion should either increase, decrease or not affect the columnar inclination angle $\beta$. Experiments clearly support the first. In the following we will therefore use Hara's model, although it might be right for the wrong reason.

Table 1

Enthalpy, entropy and heat capacity changes calculated from vapour pressure data (Eq. (6))

\begin{tabular}{|c|c|c|c|c|c|c|c|c|}
\hline \multirow[t]{2}{*}{ Metal } & \multicolumn{3}{|l|}{ [34] } & \multicolumn{3}{|l|}{ [39] } & \multicolumn{2}{|l|}{$[40]$} \\
\hline & 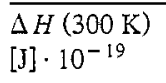 & $\begin{array}{l}\Delta S(300 \mathrm{~K}) \\
{\left[\mathrm{JK}^{-1}\right] \cdot 10^{-22}}\end{array}$ & $\begin{array}{l}\Delta C_{\mathrm{p}} \\
{\left[\mathrm{JK}^{-1}\right] \cdot 10^{-23}}\end{array}$ & $\begin{array}{l}H(300 \mathrm{~K}) \\
{[\mathrm{J}] \cdot 10^{-19}}\end{array}$ & $\begin{array}{l}\Delta S(300 \mathrm{~K}) \\
{\left[\mathrm{JK}^{-1}\right] \cdot 10^{-22}}\end{array}$ & $\begin{array}{l}\Delta C_{\mathrm{p}} \\
{\left[\mathrm{JK}^{-1}\right] \cdot 10^{-23}}\end{array}$ & $\begin{array}{l}\overline{\Delta H} \\
{[\mathrm{~J}] \cdot 10^{-19}}\end{array}$ & $\begin{array}{l}\Delta S \\
{\left[\mathrm{JK}^{-1}\right] \cdot 10^{-22}}\end{array}$ \\
\hline Co & 7.118 & 2.727 & -3.31 & 7.045 & 2.480 & -19.4 & 6.711 & 2.168 \\
\hline $\mathrm{Ni}$ & 7.613 & 3.235 & -5.75 & 7.128 & 2.528 & -25.1 & 6.664 & 2.184 \\
\hline $\mathrm{Fe}$ & 7.139 & 2.968 & -4.81 & 6.867 & 2.542 & -26.8 & 6.349 & 2.085 \\
\hline $\mathrm{Cr}$ & 6.972 & 3.100 & -5.21 & 6.587 & 2.500 & -30.7 & 6.358 & 2.2 \\
\hline
\end{tabular}


There is much less controversy on the remaining features of the morphology and texture; the bundling of the columns can be simply explained from geometrical considerations. Therefore, it is unnecessary to use the conservation of parallel momentum to explain bundling, as was suggested by Hara et al. The cross-sectional shape of the columns is only treated by van de Waterbeemd and Oosterhout [20]. Also, only one sufficiently detailed model is found for the texture of obliquely evaporated films [32].

\section{Process parameters and surface diffusion}

The major conclusion that must be drawn from the models discussed above is that surface diffusion plays a major role in film growth, which is of course well known for thin film deposition, in general. In this section, surface diffusion will be discussed in more detail. An attempt is made to calculate the influence of the process parameters on the surface diffusion.

Atoms travelling from the evaporation source to the substrate either bounce back or adsorb to the film surface. At that point, they will be called adatoms. The energy of the vapour atoms is much higher than the energy of the atoms in the film. The newly arrived adatoms will therefore have an excess-energy. For surface diffusion, one must distinguish between the period when the adatoms still have an excess energy and are transferring it to the film surface (Section 3.1) and the period when they are in equilibrium with the film surface (Section 3.2). These calculations lead to a list of key parameters which determine surface diffusion (Section 3.3).

\subsection{Adatoms before equilibrium: directional surface diffu- sion}

Assume a one-dimensional chain of surface atoms of mass $m$ and coupled by a spring constant $\kappa$. Let one atom be displaced from its equilibrium position (Fig. 12). When the displacement is small, the atom will start vibrating at a frequency of [21]:

$\varpi=\sqrt{\frac{\kappa}{m}}[\mathrm{~Hz}]$

Lennard-Jones $[21,22]$ estimates the frequency of vibration to be at least $10^{12} \mathrm{~Hz}\left(2 \cdot 10^{13}\right.$ for $\left.\mathrm{Na}\right)$. After each period of vibration, the excess energy of the displaced atom has fallen to about a quarter its former value, so after a few vibrations all the excess energy is transferred to the other atoms in the chain. These results are in agreement with

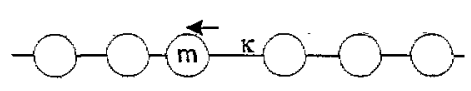

Fig. 12. Due to a laterai displacement the atoms will start vibrating. more complex quantum-mechanical calculations. According to Lennard-Jones' calculations, an atom which arrives perpendicular to the film surface will loose its excess energy in a few nanoseconds and travel only a few atomic distances during the period of accommodation.

The situation could be different for an atom arriving obliquely at the film surface. To become an adatom it only needs to loose its component of kinetic energy perpendicular to the film surface, but it can keep its parallel component. This has been called conservation of parallel momentum in the former paragraph [23]. So the possibility exists that obliquely arriving atoms will travel much faster in the case of perpendicular incidence.

According to Lennard-Jones [21,22], the energy lost in the perpendicular direction is taken up by the parallel direction, which in fact means conservation of total momentum. In that case, at perpendicular incidence, the atoms will scatter in all directions parallel to the film surface depending on what side of the surface atoms they hit. With an increasing angle of incidence, they will scatter more in the direction parallel to the projection of the vapour beam onto the film surface.

Whether the component of kinetic energy perpendicular to the film surface is lost or taken up by the parallel component, the atoms will show increasing directional surface diffusion when the angle of deposition increases.

\subsubsection{Kinetic energy vapour atoms}

The total kinetic energy of the vapour atoms will determine the amount of excess energy and the time of accommodation with the film surface. In the following, we will show that the kinetic energy of the vapour atoms is almost independent of the source temperature for practical rates of evaporation.

Background pressures used in evaporation equipment are such that the mean free path is much larger than the distance the atoms have to travel from source to substrate. The kinetic energy of the atoms arriving at the substrate is therefore the same as when they left the liquid metal of the evaporation source.

3.1.1.1. Escape energy. To leave the source, the metal atoms need an escape energy $E_{\mathrm{e}}$ which can be translated into an escape velocity $v_{\mathrm{e}}\left(E_{\mathrm{e}}=1 / 2 m v_{\mathrm{e}}^{2}\right)$. The escape energy, or heat of evaporation, can be estimated from vapour pressure data [42]. Assume a closed system containing a liquid and its vapour in equilibrium. The vapourpressure will be highly dependent on the temperature of the system. Vapour pressure data for various materials can be found in tables, e.g., in Glang [42].

It can be shown that the free energy change of the system $\Delta G$ at temperature $T$ is related to the change in enthalpy $\Delta H$ and the change in entropy $\Delta S$ :

$$
\Delta G=\Delta H-T \Delta S[\mathrm{~J}]
$$


The change in enthalpy $\Delta H$ is the value of interest $E_{\mathrm{e}}$. The change in free energy can be calculated from the vapour pressure $p^{*}\left[\mathrm{~Pa}=1 \cdot 10^{-5} \mathrm{~atm}\right]$ by:

$\Delta G=-k T \ln \left(\frac{p^{*}}{10^{5} \mathrm{~Pa}}\right)[\mathrm{J}]$

The temperature dependence of the change in enthalpy and entropy are given by the partial differential equations:

$$
\begin{aligned}
& \frac{\partial(\Delta H)}{\partial T}=\Delta C_{\mathrm{p}}\left[\mathrm{JK}^{-1}\right] \\
& \frac{\partial(\Delta S)}{\partial T}=\frac{\Delta C_{\mathrm{p}}}{T}\left[\mathrm{JK}^{-2}\right]
\end{aligned}
$$

where $\Delta C_{\mathrm{p}}$ is the difference in heat capacity of the gas and liquid phase at constant pressure. (In case of sublimation, rather than evaporation, $\Delta C_{\mathrm{p}}$ is related to the heat capacity of the solid phase). We assume the value of $\Delta C_{\mathrm{p}}$ to be independent of the temperature. A refinement only makes sense if the vapour pressure data is measured over a larger temperature than usually is given $(200 \mathrm{~K}$ for $\mathrm{Co}$, for instance, [42]). Solving Eq. (5) we obtain:

$$
\begin{aligned}
& \Delta H(T)=\Delta H\left(T_{\mathrm{o}}\right)+\Delta C_{\mathrm{p}}\left(T-T_{\mathrm{o}}\right)[\mathrm{J}] \\
& \Delta S(T)=\Delta S\left(T_{\mathrm{o}}\right)+\Delta C_{\mathrm{p}} \ln \left(\frac{T}{T_{\mathrm{o}}}\right)\left[\mathrm{JK}^{-1}\right]
\end{aligned}
$$

Where $T_{0}>0$ can be conveniently chosen.

The change in free energy is obtained by inserting Eq. (6) in Eq. (3). Fig. 14 shows the fit of the free energy to the free energy calculated from to the vapour pressure data of Co given by Glang using Eq. (4). The temperature dependence of the escape energy $E_{\mathrm{e}}$, which is equal to $\Delta H$, is shown in Fig. 13.

Table 1 lists for some metals the values of $\Delta H$ and $\Delta S$ at $300 \mathrm{~K}$, and $\Delta C_{\mathrm{p}}$ that were obtained from fitting the vapour pressure data given by Glang who obtained his data from Honig [43]. In the same table, values given by Weast et al. [39] are listed. The enthalpy $(\Delta H)$ and entropy $(\Delta S)$ values agree within reasonable limits, but the value for the heat capacity $\left(\Delta C_{\mathrm{p}}\right)$ is higher by a factor of 10 . Setting the value of the heat capacity to zero, like Roth [40] has done, gives substantially lower values of $\Delta H$. This can be seen

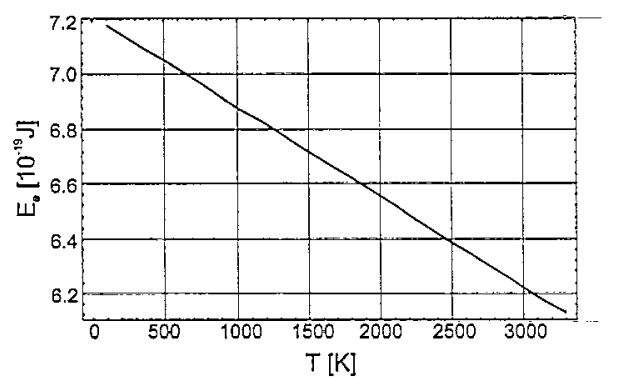

Fig. 13. Temperature dependence of escape energy of Co atoms from Co surface.

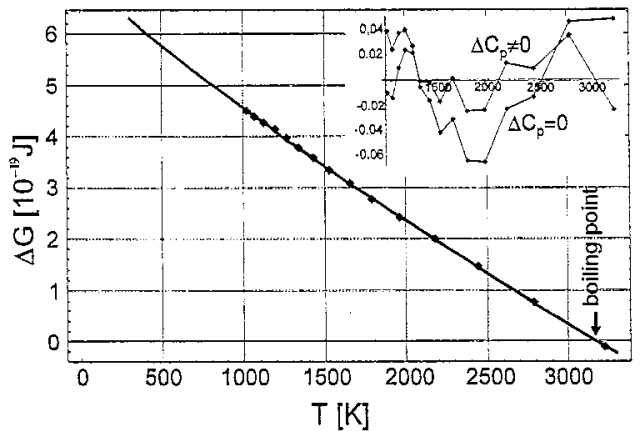

Fig. 14. Fit of free energy function with free energy data for Co calculated from a vapour pressure data table [42]. The inset shows the difference between the data-points for a fit with $\Delta C_{\mathrm{p}}=0$ and $\Delta C_{\mathrm{p}} \neq 0$.

in the fits of the vapour pressure data too, a fit including $\Delta C_{\mathrm{p}}$ is better than a linear fit (inset Fig. 14) even for Co which has the lowest change in heat capacity. The uncertainty in the heat capacity difference $C_{\mathrm{p}}$ does not seem to be serious at first sight since it is much smaller than $\Delta H\left(T_{0}\right)$. However, one should note that, at common source temperatures $(2000 \mathrm{~K}), \Delta C_{\mathrm{p}} T$ is about equal to $\Delta H\left(T_{0}\right)$ and the uncertainty becomes important.

3.1.1.2. Energy distribution of atoms leaving source. The kinetic energies of the atoms in the liquid can be approximated by the Maxwell-Boltzmann distribution in the tail of the distribution [42]:

$\frac{\mathrm{d} N_{E}}{N}=\frac{2}{k T \sqrt{\pi}}\left(\frac{E}{k T}\right)^{\frac{1}{2}} \exp \left(-\frac{E}{k T}\right) \mathrm{d} E=\phi(E) \mathrm{d} E[]$

where $N_{E}$ is the number of atoms having energy $E[\mathrm{~J}], N$ the total number of atoms in the source, $T$ the source temperature $[\mathrm{K}]$ and $k$ Boltzmann's constant $\left[\mathrm{JK}^{-1}\right]$.

The source temperature for the evaporation of $\mathrm{Co}$ or $\mathrm{Ni}$ lies in-between 2000 and $3000 \mathrm{~K}$. Fig. 15 shows the distribution function $\phi$ for different source temperatures. In the inset, an enlargement is made for energies around the escape energy for Co atoms from a Co melt. (Note that

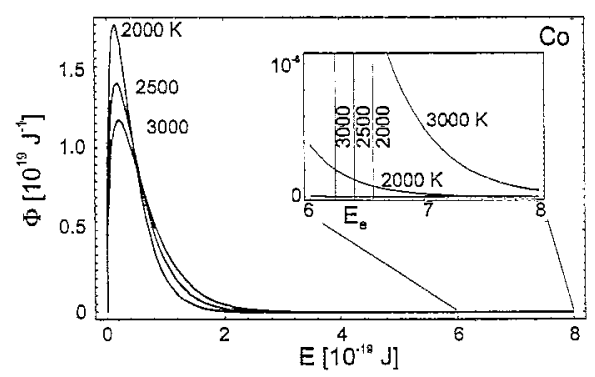

Fig. 15. Distribution of atoms with energy $E$ in a liquid at different temperatures. The inset shows the distribution around the escape energy of Co atoms from a Co melt. Only very few atoms have an energy larger than $E_{e}$ and can escape. 
$E_{\mathrm{e}}$ also varies with temperature). Only very few atoms have an energy larger than $E_{\mathrm{e}}$ and can escape.

Since only atoms at the tail of the Maxwell-Boltzmann curve can escape, the distribution in energy of atoms leaving the melt is very narrow and close to the escape energy. This is illustrated in Fig. 16 where the average energy of the atoms leaving the source and the escape energy are plotted against the source temperature. The average energy is only about $3 \%$ higher than the escape energy and the decline in the average kinetic energy over a temperature range of $1000 \mathrm{~K}$ is less than $4 \%$. Thus it is almost independent of the source temperature. The average energy of the atoms after leaving the melt (the energy is converted into kinetic energy when traveling towards the substrate) is about $0.210^{-19} \mathrm{~J}$ and is also almost independent of the source temperature.

\subsection{Adatoms in equilibrium: random surface diffusion}

Even after the adatoms have lost all their excess energy, they will continue migrating over the film surface but now in a random way. The adatoms hop from site to site. The mean time between hops $(\tau)$ is determined by the film temperature $\left(T_{\mathrm{f}}\right)$, the energy needed for one hop $\left(E_{\mathrm{h}}\right)$ and the lattice vibration frequency $\varpi(2)$ [44]:

$\tau_{\mathrm{h}}=\frac{1}{\varpi} \exp \left(\frac{E_{\mathrm{h}}}{k T_{\mathrm{f}}}\right)[\mathrm{s}]$

If the adatoms are not buried under newly arriving atoms, they will eventually re-evaporate. The mean time before reevaporation $\left(\tau_{e}\right)$ is determined by the same type of equation with $E_{\mathrm{h}}$ replaced by the activation energy for escape of an adatom from the film surface $E_{\mathrm{e}}$;

$\tau_{c}=\frac{1}{\omega} \exp \left(\frac{E_{e}}{k T_{f}}\right)[s]$

The energies $E_{\mathrm{b}}$ and $E_{\mathrm{e}}$ depend on the surroundings of the adatom. A distinction has to be made between adatoms migrating on the substrate surface (glass, silicon etc.) during the film nucleation stage and adatoms migrating on atoms of the same type during film growth.

The nucleation stage, although it persists only during a fraction of the total evaporation time, has a major influ-

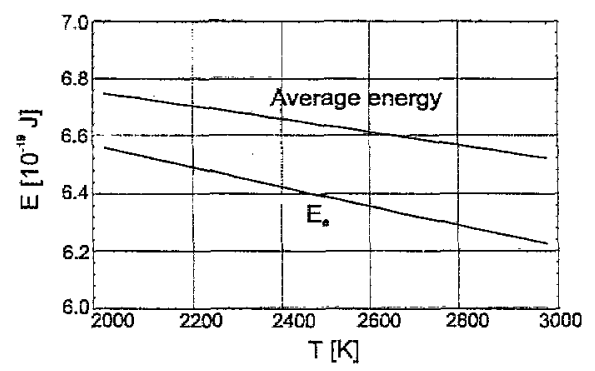

Fig. 16. Average energy of Co atoms leaving the source and escape energy versus source temperature.

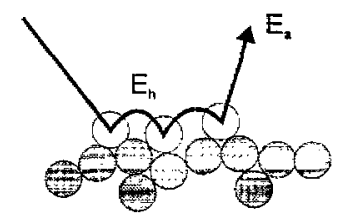

Fig. 17. The adatoms will migrate over the film surface by a hopping mechanism and re-evaporate if they are not buried under newly arriving atoms.

ence on the film structure because nucleation determines film properties like defects, column size, crystal orientation etc. Unfortunately, little is known on hop and escape energies for (metal) atoms on nonmetal substrates [45]. The only remark one can make is that surface diffusion during nucleation is larger than during film growth since metal-metal bonds are stronger than metal-glass or metal-silicon bonds (Fig. 17).

After the nucleation and coalesence stage, the impinging atoms will mainly see only metal surface atoms. In the case of single component evaporation, one can estimate the escape energy $E_{\mathrm{c}}$ from the energy needed to change the phase of the metal from liquid to gas (heat of evaporation) as was shown in the former paragraph (Table 1).

It has been found that the energy for surface diffusion $E_{\mathrm{h}}$ is about one fifth of the escape energy [45]. So, from the heat of evaporation both $E_{\mathrm{e}}$ and $E_{\mathrm{h}}$ can be estimated.

The mean time between hops has been plotted with Co as an example in Fig. 18. Around room-temperature, the adatoms hop once per second. The mean time before evaporation is larger than $10^{1 / 4} \mathrm{~s}$, which is equivalent to never.

\subsubsection{Self-diffusion distance}

The adatoms will not continue hopping over the film surface. At some point they will be buried under newly arriving vapour atoms (during deposition) or they will be trapped by chemisorption (after deposition, possibly even during). Both effects increase the energy needed for the hop to a level where hopping becomes unlikely.

3.2.1.1. Burial rate. The hopping of the adatoms is stopped by the arrival of new atoms on top of them. The distance the adatoms can travel over the film surface is therefore governed by the deposition rate. One can define the rate of deposition by the time it takes to grow one atomic layer $\tau_{\mathrm{m}}$ :

$\tau_{\mathrm{m}}=\frac{a_{\mathrm{d}}}{r}[\mathrm{~s}]$

where $a_{\mathrm{d}}[\mathrm{m}]$ is the average distance between atoms in the film measured in the direction perpendicular to the substrate surface (which for a film with bulk density will be close to the lattice spacing), and where $r[\mathrm{~m} / \mathrm{s}]$ is the deposition rate. 


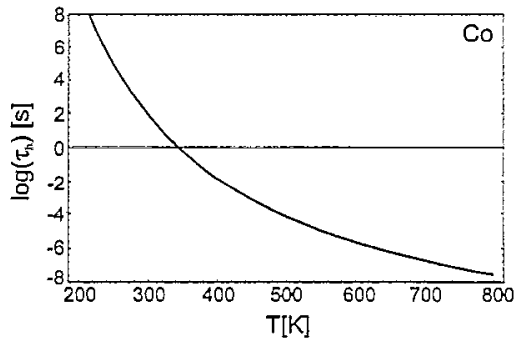

Fig. 18. Mean time between hops for Co atoms on a Co surface versus temperature.

One can define the burial rate $r_{\mathrm{b}}$ as the rate at which the time between atomic layer formation $\tau_{\mathrm{m}}$ equals the mean time between hops $\tau_{\mathrm{h}}$ :

$r_{\mathrm{b}}=a_{\mathrm{d}} \varpi \exp \left(\frac{-E_{\mathrm{h}}}{k T_{\mathrm{f}}}\right)\left[\mathrm{ms}^{-1}\right]$

Fig. 19 shows the burial rate for Co as a function of film temperature ( $a_{\mathrm{d}}$ was taken equal to the atomic radius of Co, $0.125 \mathrm{~nm}$ ). Surprisingly, the burial rate has realistic values for films prepared just above room temperature.

If the rate is much higher than the burial rate, the adatoms will not have the time to hop. If the rate is lower than the burial rate, the adatoms will make a certain number of jumps. Fig. 20 shows the average number of jumps $i$ as a function of film temperature and rate.

With every jump, the adatom moves over the distance of one absorption site $a_{\mathrm{h}}[\mathrm{m}]$. The adatoms will perform a random walk over the film surface and diffuse away from their impingement spot. The average diffusion distance or self-diffusion distance $\Lambda$, can be expressed as [46]:

$\Lambda=\frac{1}{2} a_{\mathrm{h}} \sqrt{\frac{\tau_{\mathrm{m}}}{\tau_{\mathrm{h}}}}[\mathrm{m}]$

Leading to:

$\log (\Lambda)=\log \left(\frac{1}{2} a_{\mathrm{h}} \sqrt{a_{\mathrm{d}} \varpi}\right)-\frac{E_{\mathrm{h}}}{2 k T_{\mathrm{f}}} \log (e)-\frac{1}{2} \log (r)[]$

The self-diffusion distance for Co on a Co surface is shown in Fig. 21 as a function of rate with film temperature as a parameter. ( $a_{\mathrm{d}}$ and $a_{\mathrm{h}}$ were taken equal to the

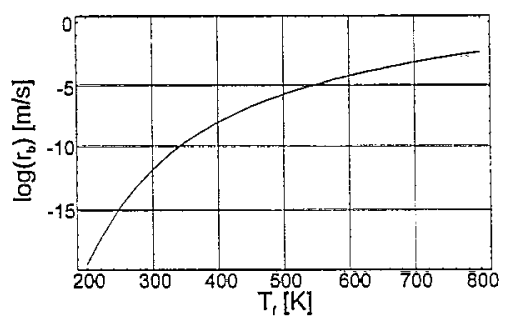

Fig. 19. Burial rate: the rate at which the average time needed for the deposition of one atomic layer equals the mean time between hops. The figure shows the very steep dependency on film temperature.

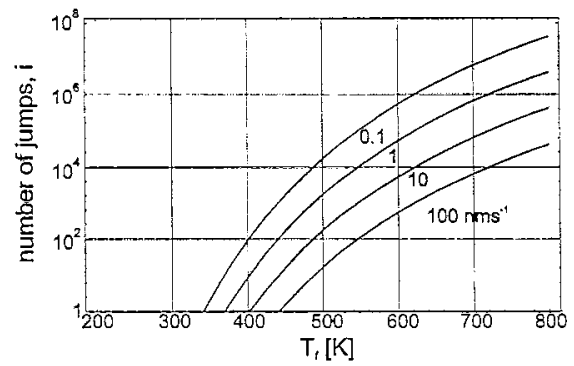

Fig. 20. Average number of jumps of adatoms as a function of film temeprature and rate.

atomic radius of $\mathrm{Co}, 0.125 \mathrm{~nm}$ ). When the rates are low and the film temperatures are high, the self-diffusion length becomes unrealistically high. At these large diffusion distances, surface roughness should be taken into account. The graph does indicate a trend but should be used with precaution.

\subsubsection{Contamination coverage}

Depending on background pressure, a certain number of atoms or molecules from residual gasses in the evaporation chamber will adsorb on the growing surface. The residual gasses in the high vacuum chamber are mainly $\mathrm{H}_{2} \mathrm{O}$ and smaller amounts of $\mathrm{CO}, \mathrm{CO}_{2}, \mathrm{~N}_{2}, \mathrm{O}_{2}$ and $\mathrm{H}_{2}$. In evaporators equipped with diffusion pumps, hydrocarbons originating from the pump fluid are also found [42]. In ultra-high vacuum, the main background gas is $\mathrm{H}_{2}$. Table 2 shows partial background pressures measured with a mass-spectrometer in our high-vacuum evaporator. It is expected that during evaporation the $\mathrm{H}_{2} \mathrm{O}$ concentration will even be higher due to outgassing. The number of gas molecules impinging on a surface depends on the partial gas pressure according to [42]:

$R_{\mathrm{c}}=\frac{p_{\mathrm{c}}}{\sqrt{2 \pi m k T_{\mathrm{f}}}}\left[\mathrm{atm}^{-2} \mathrm{~s}^{-1}\right]$

where $p_{c}[\mathrm{~Pa}=0.01 \mathrm{mbar}]$ is the partial pressure of a contaminating gas and $m_{\mathrm{c}}[\mathrm{kg}]$ is the mass of the contaminating molecule $\left(3 \cdot 10^{-26} \mathrm{~kg}\right.$ for $\left.\mathrm{H}_{2} \mathrm{O}\right)$.

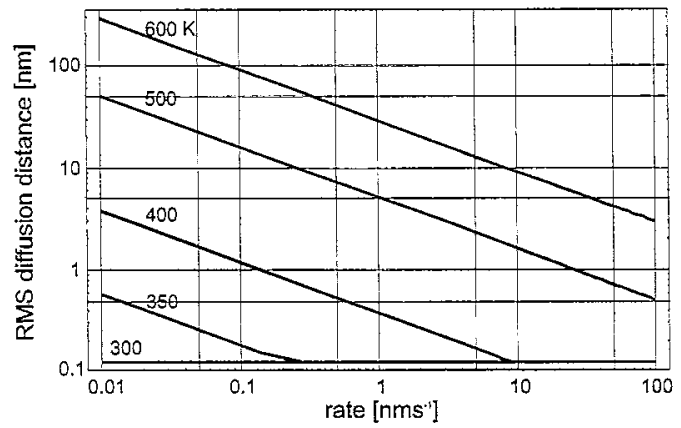

Fig. 21. Self-diffusion distance $A$ for Co adatoms on a Co surface as a function of rate $r$ and film temperature. 
Table 2

Example of partial gas pressures

\begin{tabular}{ll}
\hline Gas & Pressure $(\mu \mathrm{Pa})$ \\
\hline $\mathrm{H}_{2} \mathrm{O}$ & 36 \\
$\mathrm{~N}_{2}+\mathrm{CO}$ & 15 \\
$\mathrm{O}_{2}$ & 4.8 \\
$\mathrm{CO}_{2}$ & 2.6 \\
$\mathrm{Ar}$ & 0.6 \\
$\mathrm{H}_{2}$ & 0 \\
$\mathrm{He}$ & 0 \\
\hline
\end{tabular}

Suppose that all impinging molecules are adsorbed. They disappear from the surface either by desorption or by burial under newly arriving vapour atoms. The rate of desorption $R_{\mathrm{d}}$ is determined by the density of contaminant molecules $n_{\mathrm{c}}\left[\mathrm{atm}^{-2}\right]$ and their mean residence time $\tau_{\mathrm{d}}[\mathrm{s}]$ :

$R_{\mathrm{d}}=\frac{n_{\mathrm{c}}}{\tau_{\mathrm{d}}}\left[\mathrm{atm}^{-2} \mathrm{~s}^{-1}\right]$

$\tau_{\mathrm{d}}=\frac{1}{\varpi} \exp \left(\frac{E_{\mathrm{d}}}{k T_{\mathrm{f}}}\right)[\mathrm{s}]$

where $E_{\mathrm{d}}$ is the desorption energy for a contaminant on the film surface [J].

The rate with which contaminant molecules are buried $R_{\mathrm{b}}$ depends on the rate of evaporation $R$ and the ratio between density of contaminant molecules $n_{\mathrm{c}}$ and evaporant atoms on a clean film surface $n\left[\mathrm{~atm}^{-2}\right]$. On the assumption that each evaporant atom buries one contaminant molecule, one obtains:

$R_{\mathrm{b}}=R \frac{n_{\mathrm{c}}}{n}\left[\mathrm{~atm}^{-2} \mathrm{~s}^{-1}\right]$

The change in total contaminant density is the difference between the contaminant impingement rate and the contaminant disappearance rate, which is the sum of contaminant burial and desorption:

$\frac{\mathrm{d} n_{\mathrm{c}}}{\mathrm{d} t}=R_{\mathrm{c}}-\left(R_{b}+R_{d}\right)\left[\mathrm{atm}^{-2} \mathrm{~s}^{-1}\right]$
Assuming $R_{\mathrm{c}}, R$ and $\tau_{\mathrm{d}}$ remain constant, the solution to this differential equation is:

$$
\begin{aligned}
& n_{\mathrm{c}}=\frac{R_{\mathrm{c}}}{A}(1-\exp (-A t))\left[\mathrm{atm}^{-2}\right] \\
& A=\frac{R}{n}+\frac{1}{\tau_{\mathrm{d}}}\left[\mathrm{s}^{-1}\right]
\end{aligned}
$$

In equilibrium $(t \rightarrow \infty)$ the contamination density goes to:

$n_{\mathrm{c}}=\frac{R_{\mathrm{c}}}{\frac{1}{\tau_{\mathrm{m}}}+\frac{1}{\tau_{\mathrm{d}}}}\left[\mathrm{atm}^{-2}\right]$

where $R / n$ is substituted by $\tau_{\mathrm{m}}$, the time needed for deposition of one atomic layer of evaporant atoms. The contaminant surface density is governed by $\tau_{\mathrm{d}}$ or $\tau_{\mathrm{m}}$, whichever is smallest. The contamination level $n_{\mathrm{c}} / n$ is strongly dependent on the desorption energy of the contaminant. Table 3 lists desorption energies for some gasses on various metals. The value for $\mathrm{H}_{2} \mathrm{O}$, however, is an approximation and for gasses like $\mathrm{CO}$ and $\mathrm{CO}_{2}$ no values were found. The situation is aggravated by the fact that the partial vapour pressures that exist during evaporation are very difficult to measure. To get some grip on the problem, one could take the desorption energy as a parameter. Fig. 22 shows the surface contamination levels with an arbitrary molecule with mass $3.0 \cdot 10^{-26} \mathrm{~kg}$ for different rates and film temperatures. The film temperature determines for what desorption energy the contamination level changes from desorption-governed $\left(\tau_{\mathrm{d}}<\tau_{\mathrm{m}}\right)$ to rategoverned $\left(\tau_{\mathrm{d}}>\tau_{\mathrm{m}}\right)$, whereas the rate determines the maximum contamination level. Assuming a value for the desorption energy, we can read from these type of graphs the contamination level for a certain contaminant. If the contamination level is much smaller than unity, the contamination varies linearly with pressure and one just has to multiply the value read from the graph by the fraction the contaminant occupies in the background gasses. If, for instance, the background consists of $50 \%$ of $\mathrm{H}_{2} \mathrm{O}$ then it will occupy at $0.1 \mathrm{~nm} \mathrm{~s}^{-1}$ and $300 \mathrm{~K}$, about $40 \%$ of the total surface.

Table 3

Adsorption energies of gasses on metals and their molecular mass

\begin{tabular}{lllll}
\hline & $\mathrm{H}_{2} \mathrm{O}[42]\left[10^{-19} \mathrm{~J}\right]$ & $\mathrm{N}_{2}[47]\left[10^{-19} \mathrm{~J}\right]$ & $\mathrm{O}_{2}[47]\left[10^{-19} \mathrm{~J}\right]$ & $\mathrm{H}_{2}[47]\left[10^{-19} \mathrm{~J}\right]$ \\
\hline $\mathrm{Co}$ & $1.4-1.7$ & $3.8 \pm 0.3$ & $6.9 \pm 0.3$ & $2.1 \pm 0.3$ \\
$\mathrm{Ni}$ & $1.4-1.7$ & $4.2 \pm 0.3$ & $7.3 \pm 0.3$ & $2.1 \pm 0.3$ \\
$\mathrm{Fe}$ & $1.4-1.7$ & $5.2 \pm 0.3$ & $9.7 \pm 0.3$ & $2.1 \pm 0.3$ \\
$\mathrm{Cr}$ & $1.4-1.7$ & $6.9 \pm 0.3$ & $12.1 \pm 0.3$ & $3.1 \pm 0.3$ \\
Molecule mass & $3.0 \cdot 10^{-26} \mathrm{~kg}$ & $4.6 \cdot 10^{-26} \mathrm{~kg}$ & $5.3 \cdot 10^{-26} \mathrm{~kg}$ & $0.33 \cdot 10^{-26} \mathrm{~kg}$ \\
\hline
\end{tabular}



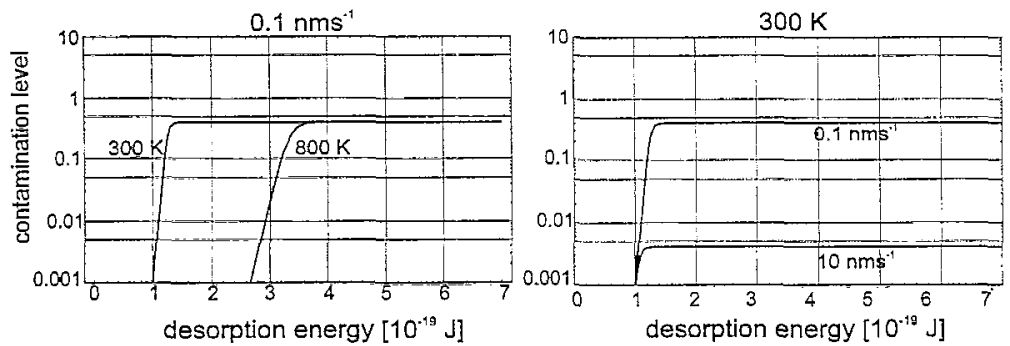

Fig. 22. Contamination levels on Co surface as function of the desorption energy of the contaminant. At low desorption energy the contamination level is governed by temperature. At high desorption energies the contamination level is governed by rate and will be built into the film. ( $m=3 \cdot 10^{-26} \mathrm{~kg}$, $p_{c}=10^{-4} \mathrm{~Pa}=10^{-6} \mathrm{mbar}$ ).

The simple model used to calculate the contamination level does not include saturation when the level reaches complete coverage. This could easily be included, but is omitted, since the exact partial pressure of molecules with a certain desorption energy is unknown. It is not very useful to refine the model if the necessary parameters cannot be obtained. Graphs like Fig. 22, therefore, should only be used as an indication: if contaminants with a given desorption energy exist, their contamination level will be influenced by the deposition parameters as indicated.

The effect of the contamination on the surface diffusion is highly dependent on the type of molecule, i.e., the binding to the metal surface. If oxygen chemisorbes to the metal surface, it has a high desorption energy. Therefore, it is likely that oxygen will limit surface diffusion. Water, on the other hand, has a low desorption energy. High water contamination levels will therefore increase surface diffusion. Increasing the film temperature from 300 to $800 \mathrm{~K}$ like in Fig. 22 will take away all $\mathrm{H}_{2} \mathrm{O}$ contamination molecules so could therefore have a decreasing effect on the surface diffusion. Increasing the rate from 0.1 to $10 \mathrm{~nm}$ $\mathrm{s}^{-1}$ at $800 \mathrm{~K}$ strongly reduces the amount of surface contamination with high desorption energies and could therefore have an increasing effect on the surface diffusion. The effect of contamination is also dependent on the actual value of the self-diffusion. If the adatoms do not move, then, of course, chemisorbtion of oxygen will not have any diffusion limiting effect.

\subsection{Operational parameters}

The detailed discussion of surface diffusion given above leads to the formulation of three key processes influencing the distance the adatoms diffuse away from their initial impingement spot.

\subsubsection{Parallel momentum}

When the direction of vapour incidence is normal to the film surface, the diffusion during the accommodation of the adatoms is a few atomic distances. Under oblique incidence, however, the diffusion is considerably larger and is in the direction given by the projection of the vapour beam direction on the film surface. The kinetic energy of the impinging vapour atoms is practically independent of the rate of evaporation and can be regarded as constant for a given process (Fig. 16). Therefore, the amount of kinetic energy (momentum) preserved in the direction parallel to the film surface is only determined by the angle of incidence.

\subsubsection{Self-diffusion distance}

After accommodation, the adatoms will start hopping over the surface until they are buried under newly arriving vapour atoms. Neglecting the influence of background gasses, an average root mean square (RMS) diffusion distance can be calculated (Eq. (12)). This diffusion has no directional component.

\subsubsection{Surface contamination level}

The presence of molecules from background gasses in the system will influence surface diffusion. Since the exact desorption energies of those molecules and the partial pressure of the background gasses are unknown, the effect of contamination cannot be calculated directly. Instead, one can calculate the change in the amount of surface contamination, with the desorption energy as a parameter, for a change in process conditions (Eq. (19)). In this way, it is possible to analyse if a change in surface diffusion can be expected.

\section{Comparison of model with measurements from liter- ature}

In the former section, an attempt was made to relate process parameters to the amount of surface diffusion. To check the validity of the theory presented, a number of experiments published in literature will be discussed here.

The most interesting structure parameter to investigate is the columnar inclination, especially the change in inclination with changing process parameters. According to Hara's model, which was selected in Section 2 as the most suitable model, the columns will grow more toward the vapour incidence direction when the surface diffusion increases. Hara et al. use a replica method to investigate the columnar inclination. The resolution of this method is not 
as good as in cross-section electron microscopy, but it is sufficient to investigate the columnar inclination. The advantage of the replica method is that it is a relatively simple method of specimen preparation so that a large number of samples can be investigated.

The research performed by Hara et al, is very extensive for iron. The process parameters have been varied over a large range. Therefore, the results obtained for $\mathrm{Fe}$ can be used to check the theory. This is done in the first part of this section.

The results obtained for $\mathrm{Co}$ and $\mathrm{Ni}$ are less complete. The difference between $\mathrm{Fe}$ and $\mathrm{Co}$ or $\mathrm{Ni}$ is not extreme. The desorption energy for $\mathrm{Co}$ and $\mathrm{Ni}$ is slightly higher than for $\mathrm{Fe}$, so the onset of diffusion will be at a slightly higher substrate temperature too. The affinity for oxygen of $\mathrm{Co}$ and $\mathrm{Ni}$ is much lower than for $\mathrm{Fe}$, so the effect of oxygen contamination will be smaller. In the second part of this section, $\mathrm{Co}$ and $\mathrm{Ni}$ will be discussed and compared to the results obtained for Fe.

\subsection{Fe}

The experiments discussed here were performed under a wide range of process conditions. The substrate temperature was varied from 100 to $900 \mathrm{~K}$, the rate was varied from 0.1 to $100 \mathrm{~nm} \mathrm{~s}^{-1}$ and the pressure during evaporation was varied from $10^{-3}$ to $1 \mathrm{~Pa}\left(10^{-5}\right.$ to $\left.10^{-2} \mathrm{mbar}\right)$.

Analysis of the data with the help of the theory developed above shows that three transition temperatures can be defined as follows:

- $T_{\text {onset }}:$ Temperature of onset of surface diffusion. This is the film temperature at which self-diffusion starts.

- $T_{\mathrm{H}_{2} \mathrm{O}}$ : Temperature of disappearance of $\mathrm{H}_{2} \mathrm{O}$ contamination. This is the film temperature at which $\mathrm{H}_{2} \mathrm{O}$ molecules have such a small residence time that they are not buried in the film. Below this temperature, the $\mathrm{H}_{2} \mathrm{O}$ contamination is relatively high and is determined by the evaporation rate. Above this temperature, the $\mathrm{H}_{2} \mathrm{O}$ contamination is low and is determined by the film temperature.

- $T_{X}$ : Temperature of disappearance of a diffusion limiting contaminant $(X)$. Like the $\mathrm{H}_{2} \mathrm{O}$ molecules, other molecules also will have their specific critical temperature. From the measured data, one must conclude that there is a contaminant with a desorption energy of $2-3 \cdot 10^{-19} \mathrm{~J}$ which limits surface diffusion. This contaminant could be $\mathrm{O}_{2}$ or $\mathrm{N}_{2}$.

The three transition temperatures define four temperature regions in which a change in background pressure or rate have completely different effects.

\subsubsection{Zone $1 T_{f}<T_{\text {onset }}$}

If the film temperature lies below the onset temperature of self-surface diffusion, the surface diffusion is determined by the $\mathrm{H}_{2} \mathrm{O}$ contamination level. The $\mathrm{H}_{2} \mathrm{O}$ molecules enable surface diffusion. An increase in $\mathrm{H}_{2} \mathrm{O}$ contamina- tion, caused by a rise in pressure or a decrease in rate, will therefore increase surface diffusion.

\subsubsection{Zone $2 T_{\text {onset }}<T_{f}<T_{\mathrm{H}_{2} \mathrm{O}}$}

If the film temperature lies above the onset temperature of self-surface diffusion, the Fe atoms already diffuse over each other so the $\mathrm{H}_{2} \mathrm{O}$ contamination will have a small effect. Other contaminants like $\mathrm{O}_{2}$ or $\mathrm{N}_{2}$ are becoming important since they could reduce surface diffusion. The $\mathrm{H}_{2} \mathrm{O}$ contamination level is nevertheless much larger and overrules the other contaminants. An increase in contamination still increases surface diffusion, but the effect is much smaller.

\subsubsection{Zone $3 T_{\mathrm{H}_{2} \mathrm{O}}<\mathrm{T}_{\mathrm{f}}<\mathrm{T}_{\mathrm{X}}$}

If the film temperature exceeds the temperature where the $\mathrm{H}_{2} \mathrm{O}$ contamination disappears, the diffusion is determined by other contaminants with a much higher desorption energy such as $\mathrm{N}_{2}$ and $\mathrm{O}_{2}$. These contaminants reduce surface diffusion. A rise in pressure or a decrease in rate therefore decreases surface diffusion.

\subsubsection{Zone $4 T_{f}>T_{X}$}

If the film temperature is increased further, more contaminants will disappear. This has an increasing effect on surface diffusion.

Agreement between theory and measurements is only obtained if the film temperature is assumed to be about $100 \mathrm{~K}$ higher than the measured temperatures. One explanation for this discrepancy could be that the temperature of the film is $100 \mathrm{~K}$ higher than the temperature of the substrate holder. This could be the case if the contact between the sample and the sample-holder is poor. Another possibility is that both the hopping energy of the Fe atoms and the desorption energy of the contaminants are overestimated.

Table 4 lists the transition temperatures for Fe evaporated at a rate of $1 \mathrm{~nm} \mathrm{~s}^{-1}$ and a background pressure of 4 $\mathrm{mPa}$. Both the theoretical, as calculated from the preceding paragraph, and measured temperatures are shown. The transition temperatures are slightly dependent on the rate of evaporation.

The best illustration of the first two transition temperatures is given in Fig. 23. The substrate temperature ranges from far below room temperature to far above. Two rates of evaporation ( 1 and $10 \mathrm{~nm} \mathrm{~s}^{-1}$ ) were investigated.

The calculation of $T_{\text {onset }}$ is shown in Fig. 24 left. If the $100 \mathrm{~K}$ temperature correction is taken into account, the

Table 4

Transition temperatures $\left(p=4 \mathrm{mPa}, r=1 \mathrm{~nm} \mathrm{~s}^{-1}\right)$

\begin{tabular}{lll} 
& Measured $(\mathrm{K})$ & Theoretical $(\mathrm{K})$ \\
\hline$T_{\text {onset }}$ & 250 & 350 \\
$T_{\mathrm{H}_{2} \mathrm{O}}$ & 330 & 430 \\
$T_{\mathrm{X}}$ & 600 & 700 \\
\hline
\end{tabular}




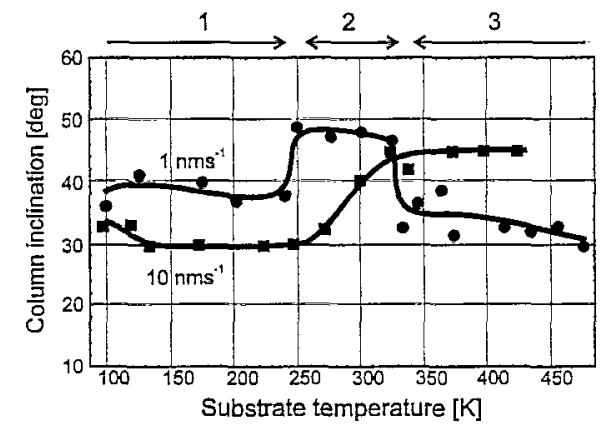

Fig. 23. Columnar inclination $\mathrm{b}$ as a function of substrate temperature $T$, and at rates of $1 \mathrm{nms}^{-1}$ (circles) and $10 \mathrm{nms}^{-1}$ (squares) [24,48]. (Fe, 60', $\left.4 \mathrm{mPa}\left(4 \mathrm{v} 6.3110^{-5} \mathrm{mbar}\right)\right)$.

increase in columnar inclination at $250 \mathrm{~K}$ in Fig. 23 can be explained by the onset of surface diffusion, thus the transition from zone 1 to 2 . The observation made from Fig. 23 that $T_{\text {onset }}$ does seem to have higher value for higher rate of evaporation is in agreement with the calculation. An increase in the rate of evaporation in zone $1\left(T<T_{\text {onset }}\right)$ causes a decrease in columnar inclination due to the decrease in $\mathrm{H}_{2} \mathrm{O}$ contamination.

Calculations of the $\mathrm{H}_{2} \mathrm{O}$ contamination level are shown in Fig. 25. Depending on the choice for the desorption energy, the $\mathrm{H}_{2} \mathrm{O}$ contamination level drops below $5 \%$ somewhere between 400 and $500 \mathrm{~K}$. If again the $100 \mathrm{~K}$ correction is made, the disappearance of $\mathrm{H}_{2} \mathrm{O}$ contamination can be held responsible for the drop in columnar inclination at $330 \mathrm{~K}$ of the $1 \mathrm{~nm} \mathrm{~s}^{-1}$ curve in Fig. 23. This is the transition from zone 2 to 3 . The $10 \mathrm{~nm} \mathrm{~s}^{-1}$ curve is less affected since the $\mathrm{H}_{2} \mathrm{O}$ contamination level at this point is already low. Thus, an increase in rate has exactly the opposite effect. The reduction in contamination (with $\mathrm{O}_{2}$ or $\mathrm{N}_{2}$, Fig. 24 right) causes an increase in surface diffusion which on its turn causes an increase in columnar inclination.

As expected, the amount of bundling is closely correlated to the columnar inclination. The bundling disappears in the region between 250 and $330 \mathrm{~K}$ for a rate of $1 \mathrm{~nm}$ $\mathrm{s}^{-1}$. Bundling is observed for substrate temperatures below $250 \mathrm{~K}$ for a rate of $10 \mathrm{~nm} \mathrm{~s}^{-1}$.

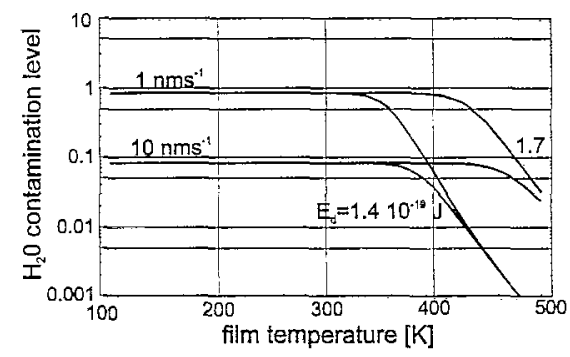

Fig. 25. Surface contamination level with $\mathrm{H}_{2} \mathrm{O}$ molecules $\left(E_{\mathrm{d}}=1.4-1.7\right.$. $\left.10^{-19} \mathrm{~J}\right)$ as a function of substrate temperature and rate. The partial $\mathrm{H}_{2} \mathrm{O}$ pressure was taken to be $2 \mathrm{mPa}$.

The texture of the films shows a different dependence on the film temperature for the two rates. At a rate of $1 \mathrm{~nm}$ $\mathrm{s}^{-1}$, a steady increase of degree of texture orientation for substrate temperatures over $300 \mathrm{~K}$ is observed. The texture is either $[100](010)$ or $[111](1 \overline{10})$, the texture inclination was not published. At $10 \mathrm{~nm} \mathrm{~s}{ }^{-1}$, the degree of texture orientation shows a maximum at $200 \mathrm{~K}$. The texture orientation is $[100](010)$ and the texture inclination is $60^{\circ}$. It seems as if the degree of orientation increases with a decrease in columnar inclination. Whether there is a direct correlation or this is caused by the decrease in surface diffusion is unclear.

The expected effect of contamination in zone 3 is confirmed by the measurements of Fig. 26. Clearly, a rise in pressure has the same effect as a decrease in rate. They both increase the contamination level (Fig. 27). Since the substrate temperature lies above $T_{\mathrm{H}_{2} \mathrm{O}}$, contamination causes a decrease in surface diffusion which, on its turn, causes a decrease in columnar inclination. The relation between background pressure and columnar inclination is confirmed at an incidence angle of $45^{\circ}$ [29]. Judging from the saturation which seems to occur at $10^{-2} \mathrm{~Pa}$ in the pressure experiment and at $1 \mathrm{~nm} \mathrm{~s}^{-1}$ in the rate experiment, the contaminant, which limits surface diffusion, should have a partial pressure of less than $10 \%$ of the background pressure.

At pressures above $0.1 \mathrm{~Pa}$ the mean free path of the gas molecules in the vacuum system drops below $10 \mathrm{~cm}$,
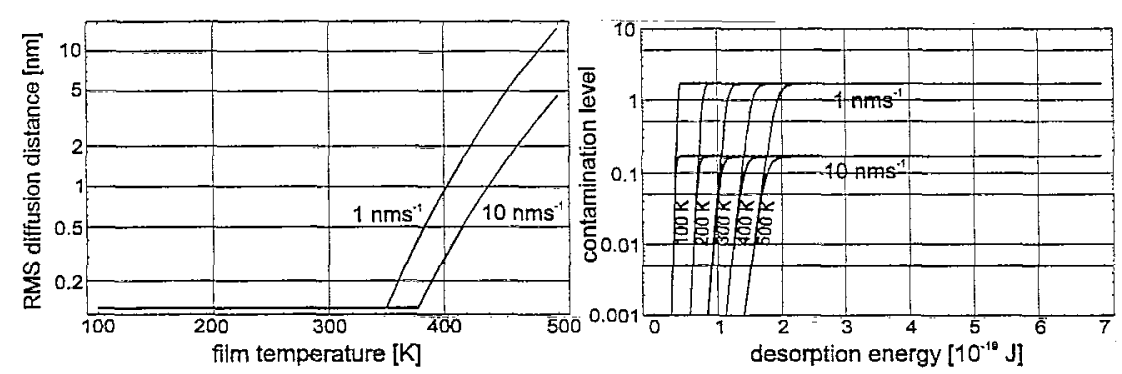

Fig. 24. Calculations of surface diffusion. Left: The onset of diffusion lies around $350 \mathrm{~K}$ for a rate of $1 \mathrm{nms}^{-1}$ and around $375 \mathrm{~K}$ for $10 \mathrm{nms}{ }^{-1}$. Right: Contamination level as function of the desorption energy of the contaminant for different substrate temperatures and rates. Process conditions as in Fig. 23. 

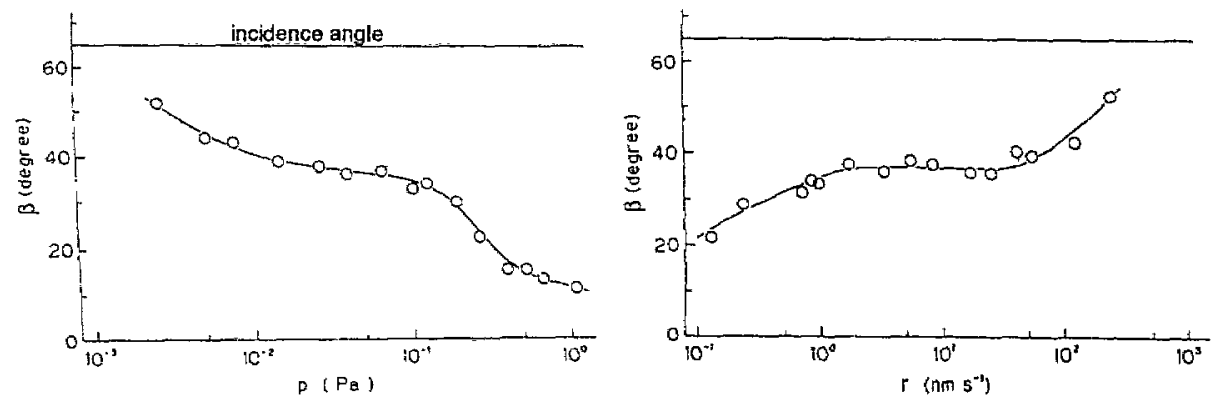

Fig. 26. Left: Columnar inclination $\beta$ as a function of background pressure $p$ ( $1 \mathrm{~Pa}=0.01 \mathrm{mbar}$ ). ([49], Fe, 65 $, 470 \mathrm{~K}, 0.85 \mathrm{~nm}^{-1}$ ), Right: columnar inclination $\beta$ as a function of deposition rate $\mathrm{r}$. ([33] $65^{\circ}, 473 \mathrm{~K}, 93 \mathrm{mPa}\left(93 \cdot 10^{-5} \mathrm{mbar}\right)$ ).

resulting in a spread in angle of vapour incidence. When the vapour atoms arrive from all sides, the columns will grow parallel to the substrate normal. This effect can be clearly seen in Fig. 26 left.

It is unclear what causes the sudden increase in columnar inclination around $50 \mathrm{~nm} \mathrm{~s}^{-1}$ (Fig. 26 right). If it is caused by a reduction in self-diffusion, the effect is in contradiction with Hara's model. As expected, the bundling was observed to become more pronounced with decreasing columnar angle so with increasing pressure or decreasing rate. At a very high rate, the bundles are observed too, even though the columnar inclination increases.

The change of texture of the films with rate or pressure is complex. For the pressure experiment, it was found that, up to $0.4 \mathrm{~Pa}$, the texture orientation is [100](010). The degree of texture orientation was found to increase with increasing pressure up to $0.04 \mathrm{~Pa}$, again there is a correlation with the columnar inclination. The increase in degree of orientation is accompanied by a slight decrease in texture axis inclination from $55^{\circ}$ down to $45^{\circ}$. According to van der Drift, by reducing surface diffusion the texture inclination should turn from about $-13^{\circ}$ (surface diffusion limited to crystallite) to $32^{\circ}$ (surface diffusion limited to the crystal planes). The measured inclinations do not correlate with those predictions at all. The [100](010) orientation, however, could also be interpreted as a [101](010) orientation. In that case, the texture axis changes from $10^{\circ}$ down to $0^{\circ}$, values closer to the prediction but still with the wrong trend.
When the influence of the reduction in mean free path becomes important, the crystal orientation changes: from 0.1 to $0.4 \mathrm{~Pa}$. The texture is $[111](1 \overline{10})$ with the texture axis perpendicular to the substrate. In addition, above 0.5 $\mathrm{Pa}$ the two degree orientation turns into a [111] one degree orientation. For the rate experiment, it was found that, at low rates, the texture is [111](1) 10$)$ with the [111] axis inclined $-10^{\circ}$ from the substrate normal (so the texture axis lies on the other side of the substrate normal compared to the column axis). With increasing rate, the texture changes to $[100](010)$ with an inclination axis close to $50^{\circ}$ at about $0.7 \mathrm{~nm} \mathrm{~s}^{-1}$. So far this seems to correspond to the pressure experiment. At higher rates, the correspondence disappears. At $1.5 \mathrm{~nm} \mathrm{~s}^{-1}$, the texture changes to [111](110) with an incination of $15^{\circ}$. The [100](010) and [111] (110) orientations coexist around $1 \mathrm{~nm} \mathrm{~s}^{-1}$. At rates above 20 $\mathrm{nm} \mathrm{s}^{-1}$, the $[100](010)$ orientation reappears with an inclination axis increasing from $50^{\circ}$ to $80^{\circ}$ with increasing rate.

At low rates, the texture inclination lies close to $-13^{\circ}$ as predicted by van der Drift for surface diffusion limited to the crystals. If we interpret the $[100](010)$ as $[101](010)$, again we see an increase in texture axis from $-10^{\circ}$ to $15^{\circ}$ at $0.7 \mathrm{~nm} \mathrm{~s} \mathrm{~s}^{-1}$ and a further increase from $15^{\circ}$ up to $25^{\circ}$ above $50 \mathrm{~nm} \mathrm{~s}^{-1}$. The texture inclination seems to go to the $32^{\circ}$ predicted by van der Drift for diffusion limited to the crystal planes, suggesting a decrease in surface diffusion. Again the wrong trend is predicted by the van der Drift model.

The transition to zone 4 is illustrated by Fig. 28. At
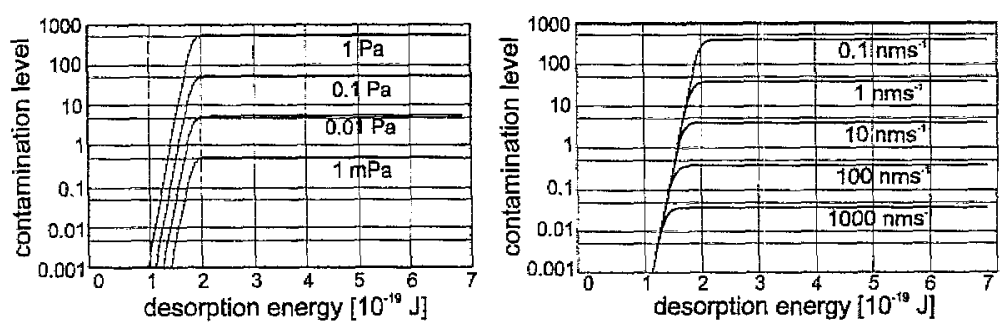

Fig. 27. Contamination level as a function of teh desorption energy of the contaminant ( $\left.E_{d}\right)$ for different background pressures (left) and rate (right). For process conditions see Fig. 26. 


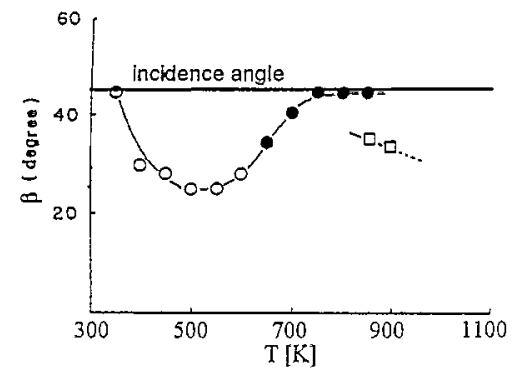

Fig. 28. Columnar inclination $\mathrm{b}$ as a function of substrate temperature $T$. The open circies represent thin columnar grains, the closed circles thick columnar grains and the squares large grains. ([50], $\mathrm{Fe}, 45^{\circ}, 4.2 \mathrm{nms}^{-1}, 4$ $\mathrm{mPa}\left(4 \cdot 10^{-5} \mathrm{mbar}\right)$.

about $600 \mathrm{~K}$, the columnar inclination decreases. This is confirmed by experiments performed at $60^{\circ}$ [51]. The increase in columnar inclination is probably caused by the disappearance of a surface diffusion limiting contaminant. It can be calculated that the desorption energy of a contaminant which disappears at $600 \mathrm{~K}$ is $2.5 \cdot 10^{-19} \mathrm{~J}$. This contaminant could be $\mathrm{H}_{2}$ which has a desorption energy of $2.1 \cdot 10^{-19} \mathrm{~J}$ (Table 3 ). The amount of $\mathrm{H}_{2}$ in an ordinary high vacuum system, however, is very low and it is hard to imagine how $\mathrm{H}_{2}$ decreases surface diffusion.

If one assumes that the film temperature is actually 100 $\mathrm{K}$ higher, the desorption energy would be about $3 \cdot 10^{-19}$ J. In that case, $\mathrm{N}_{2}\left(3.8 \cdot 10^{-19}\right)$ could be a candidate, perhaps forming a nitride $\left(\mathrm{Fe}_{4} \mathrm{~N}\right)$. The bundling and degree of texture orientation again show a maximum at minimum columnar inclination $(500 \mathrm{~K})$. At $800 \mathrm{~K}$, bulk diffusion starts [52] and the columnar structure disappears, as indicated by the squares in Fig. 28 .

\section{2. $\mathrm{Co}, \mathrm{Ni}$ and $\mathrm{CoNi}$}

Pure Fe films are less interesting for application as a medium for magnetic recording, which is the field of research of the authors. The oblique evaporation effect is used for the production of Metal Evaporated tape, which consists of partially oxidised $\mathrm{Co}_{80} \mathrm{Ni}_{20}$ or $\mathrm{Co}$. Published data on columnar inclination in obliquely evaporated $\mathrm{Co}$ films are less complete than for $\mathrm{Fe}$. For $\mathrm{Co}_{80} \mathrm{Ni}_{20}$, no experiments were found where the columnar inclination

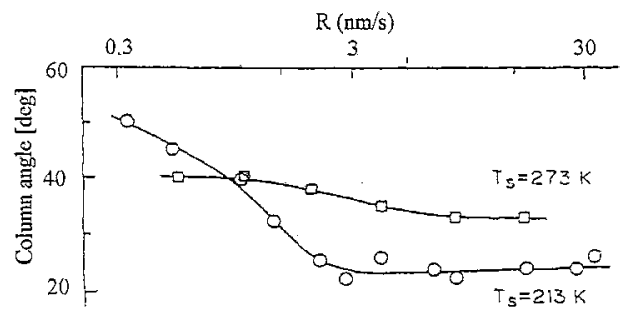

Fig. 29. Experiment with Co. Columnar inclination $\beta$ versus deposition rate $r$ for different substrate temperatures $T$. ([53], Co, $60^{\circ}, 4 \mathrm{mPa}$ ).

was measured as a function of a process parameter. Since $\mathrm{Co}$ and Ni have very similar properties, experiments with Co are interesting especially when the results obtained for Co are compared with those for $\mathrm{Fe}$.

First, the difference between $\mathrm{Co}$ and $\mathrm{Fe}$ will be discussed after which $\mathrm{Ni}$ and the CoNi alloy will be treated.

\subsubsection{Difference between $\mathrm{Co}$ and $\mathrm{Fe}$}

Fig. 29 shows the change in columnar inclination of $\mathrm{Co}$ with a change in rate of evaporation for two different substrate temperatures. Like in the case with $\mathrm{Fe}$, the agreement with Hara's model is obtained if the actual film temperature is assumed $100 \mathrm{~K}$ higher than the substrate temperature. The experiment at $213 \mathrm{~K}$ is definitely in zone $1\left(T<T_{\text {onset }}\right)$. An increase in rate decreases the $\mathrm{H}_{2} \mathrm{O}$ contamination which decreases surface diffusion. The effect of contamination is opposite in Fig. 26 since there the film temperature lies in zone 3.

At $273 \mathrm{~K}$, the substrate temperature is close to $T_{\text {onset }}$ (Fig. 29 left) explaining why at high rates the columnar inclination is larger for $273 \mathrm{~K}$ than for $213 \mathrm{~K}$. At low rates, the $\mathrm{H}_{2} \mathrm{O}$ contamination, and therefore the columnar inclination, will be larger for $213 \mathrm{~K}$ (Fig. 30 right and Fig. 31). For rates above $1 \mathrm{~nm} \mathrm{~s}^{-1}$, the bundling becomes clear for the substrate temperature of $213 \mathrm{~K}$, but at $273 \mathrm{~K}$ only a slight increase in bundling is observed, as can be explained by the difference in columnar inclination. At low rates, the columns are narrow for the substrate temperature of $213 \mathrm{~K}$, indicating a low diffusion distance.

Interesting is the effect of pressure. If at a substrate temperature of $213 \mathrm{~K}$ the pressure is increased to $8 \mathrm{mPa}$, the bundling starts at a higher rate and only reaches the
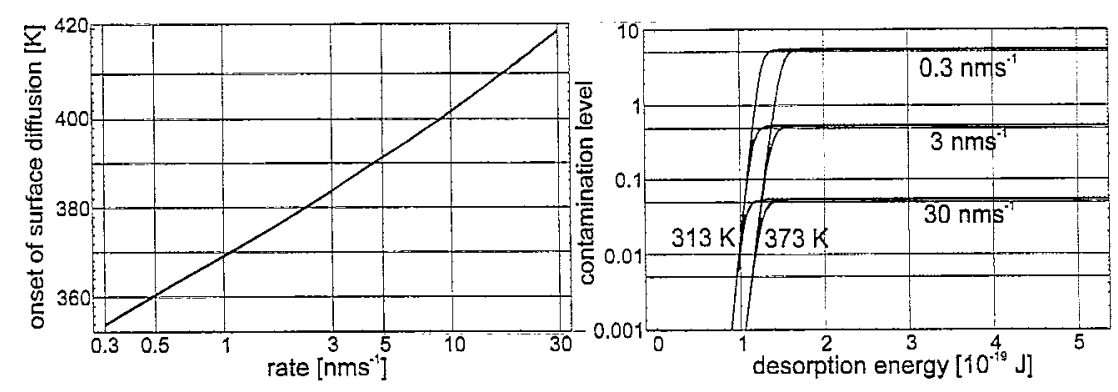

Fig. 30. Left: Film temperature at which self-diffusion starts versus deposition rate $r$. Right: Contamination level as function of the desorption energy of the contaminant (Process parameters see Fig. 29). 


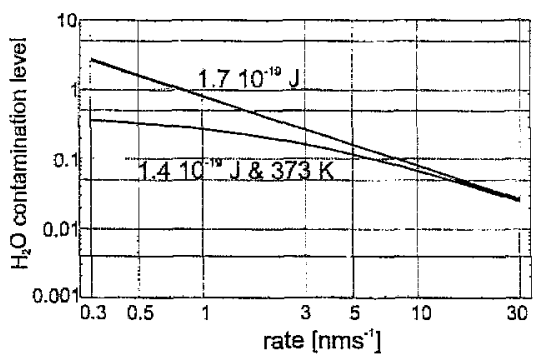

Fig. 31. Contamination with $\mathrm{H}_{2} \mathrm{O}$ molecules versus rate. When the desorption energy of $\mathrm{H}_{2} \mathrm{O}$ is taken equal to $1.7 \cdot 10^{-19} \mathrm{~J}$ the difference between a film temprature of $313 \mathrm{~K}$ and 373 is negligible.

same value as with a pressure of $4 \mathrm{mPa}$ at very high rates. This effect must be caused by the increase in partial $\mathrm{H}_{2} \mathrm{O}$ pressure. If at $4 \mathrm{mPa}$ the air is replaced by $\mathrm{N}_{2}$ bundling starts already at $0.3 \mathrm{~nm} \mathrm{~s}^{-1}$. This can be explained by the reduction in partial $\mathrm{H}_{2} \mathrm{O}$ pressure. If the $\mathrm{N}_{2}$ pressure is increased up to $40 \mathrm{mPa}$, the relation between bundling and rate is the same as for an air pressure of $4 \mathrm{mPa}$. One might conclude that $\mathrm{N}_{2}$ has a much smaller influence on surface diffusion than $\mathrm{H}_{2} \mathrm{O}$, but it still does increase surface diffusion. The effect of $\mathrm{N}_{2}$ is apparently different for $\mathrm{Fe}$ and $\mathrm{Co}$.

That the onset of surface diffusion must lie just below a substrate temperature of $300 \mathrm{~K}$ has been shown by observation of bundling ([54], 94-473 $\mathrm{K}$, rate $8 \mathrm{~nm} \mathrm{~s}^{-1}, 60^{\circ}, 4$ $\mathrm{mPa}$ ).

At a substrate temperature of $470 \mathrm{~K}$, a pressure of 4 $\mathrm{mPa}$ and an incidence angle of $70^{\circ}$, the effects of change in rate and substrate temperature are small $[55,56]$. When the rate is increased from 0.1 to $18 \mathrm{~nm} \mathrm{~s}^{-1}$ the columnar inclination drops from $60^{\circ}$ to $50^{\circ}$ at $5 \mathrm{~nm} \mathrm{~s}^{-1}$ and then slowly increases with increasing rate. The initial drop can be caused by the disappearance of $\mathrm{H}_{2} \mathrm{O}$, whereas the increase could be explained by a reduced contamination with a diffusion limiting contaminant $\left(\mathrm{O}_{2}\right)$. About the same behaviour was found when the substrate temperature was increased from 370 to $570 \mathrm{~K}$ at a rate of $2.8 \mathrm{~nm} \mathrm{~s}^{-1}$. Bundling was not observed at 0.1 and $18 \mathrm{~nm} \mathrm{~s}^{-1}$, but it was clear at $4 \mathrm{~nm} \mathrm{~s}^{-1}$.

These observations at high substrate temperature suggest that the effect of contamination is much smaller for $\mathrm{Co}$ than for $\mathrm{Fe}$, which could be related to the oxygen
Table 5

Comparison of columnar inclination angles for $\mathrm{Fe}$ and $\mathrm{Co}(p=4 \mathrm{mPa}$, $\alpha=60^{\circ}\left[70^{\circ}\right.$ for Co at $\left.470 \mathrm{~K}\right]$

\begin{tabular}{llllll}
\hline$T$ & $1 \mathrm{~nm} \mathrm{~s}^{-1}$ & & & \multicolumn{1}{l}{$10 \mathrm{~nm} \mathrm{~s}^{-1}$} \\
\cline { 2 - 3 } \cline { 5 - 6 } & $\mathrm{Fe}$ & $\mathrm{Co}$ & & $\mathrm{Fe}$ & $\mathrm{Co}$ \\
\hline $213 \mathrm{~K}$ & $38^{\circ}$ & $40^{\circ}$ & $32^{\circ}$ & $25^{\circ}$ \\
$273 \mathrm{~K}$ & $50^{\circ}$ & $40^{\circ}$ & $30^{\circ}$ & $32^{\circ}$ \\
$470 \mathrm{~K}$ & $32^{\circ}(0.36)$ & $55^{\circ}(0.52)$ & $45^{\circ}(0.57)$ & $52^{\circ}(0.47)$ \\
\hline
\end{tabular}

affinity. Table 5 shows the columnar inclination angles for equal deposition conditions at 213 and $273 \mathrm{~K}$ and for slightly different angles of incidence at $470 \mathrm{~K}$. In the latter case, $\tan (\beta) / \tan (\alpha)$ is shown between parentheses. The difference in columnar inclination at $273 \mathrm{~K}$ and $1 \mathrm{~nm} \mathrm{~s}^{-1}$ is caused by the difference in hopping-energies for $\mathrm{Co}$ and Fe. Surface diffusion starts at a higher substrate temperature for Co than for $\mathrm{Fe}$. The difference in columnar inclination at $470 \mathrm{~K}$ and $1 \mathrm{~nm} \mathrm{~s}$ s $^{-1}$ can only partially be explained by the different angles of incidence. Contamination, probably by oxygen, has a much smaller influence on the reduction of surface diffusion on Co than on Fe. On the other hand, increasing the rate at $213 \mathrm{~K}$ has a much larger effect on Co than on Fe. This could be caused by a lower desorption energy of $\mathrm{H}_{2} \mathrm{O}$ on a Co surface. This supports the conclusion one can draw from Fig. 31 that the desorption energy for $\mathrm{H}_{2} \mathrm{O}$ on $\mathrm{Co}$ must lie closer to 1.4 than to $1.7 \cdot 10^{-19} \mathrm{~J}$.

$\mathrm{Co}$ has a hexagonal texture whereas $\mathrm{Fe}$ is cubic. The results of texture investigations are therefore different for Co. In the Co films prepared at $70^{\circ}$ incidence and substrate temperatures above $370 \mathrm{~K}$, two texture orientations were found [56]. Both textures can exist simultaneously in one film. One can discriminate between initial orientation with its $c$-axis $30^{\circ}$ from the substrate normal and a final orientation which develops as the films grows and has its $c$-axis in the film plane. Below substrate temperatures of $470 \mathrm{~K}$, the initial stage is thin and the films are mainly in the final orientation. Above $520 \mathrm{~K}$, the films are mainly in the initial orientation. At a substrate temperature of $213 \mathrm{~K}$ and an incidence angle of $60^{\circ}$, the $c$-axis points in the vapour incidence direction, independent of the rate of evaporation [57]. When the substrate temperature is increased from 100
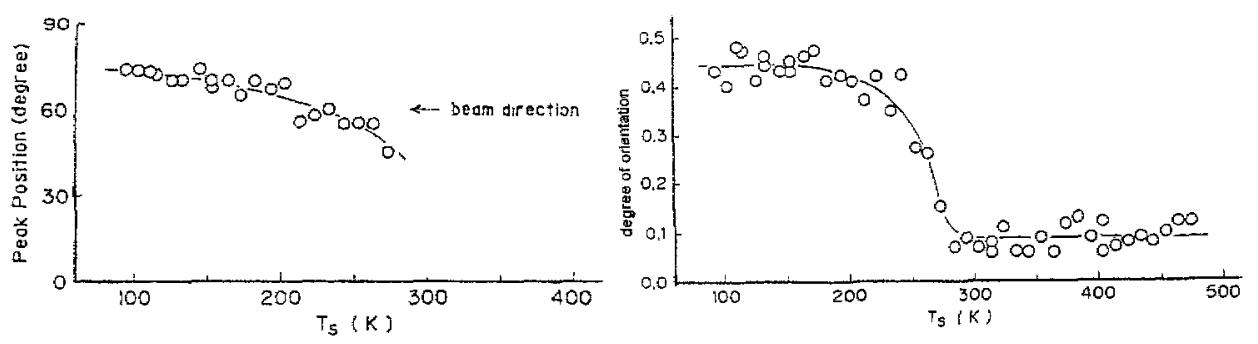

Fig. 32. Data obtained from X-ray diffraction pole figure measurements. Left: Inclination of main c-axis direction from substrate normal (Peak position of [0001] pole figure), Right: Degree of orientation. ([48], $\left.\mathrm{Co}, 60^{\circ}, 8 \mathrm{nms}^{-1}, 4 \mathrm{mPa}\right)$, 
to $280 \mathrm{~K}$ (Fig. 32) the main $c$-axis direction drops from $70^{\circ}$ to $45^{\circ}$, above $280 \mathrm{~K}$ the degree of orientation in $c$-axis distributions drops to zero and a main $c$-axis orientation could not be observed [54].

According to van der Drift, the inclination of the texture axis for an angle of incidence of $70^{\circ}$ is $-10^{\circ}$ for surface diffusion limited to the crystals and $35^{\circ}$ degree for diffusion limited to the crystal planes, assuming an angle-independent condensation coefficient. At an incidence angle of $60^{\circ}$, these values are $-15^{\circ}$ and $30^{\circ}$, respectively. Like Fe, there may not be any correlation with the experiments.

\subsubsection{Ni and $\mathrm{CoNi}$}

$\mathrm{Ni}$ has a higher desorption energy than Co but the difference is not as big as between $\mathrm{Co}$ and $\mathrm{Fe}$. The onset of surface diffusion for $\mathrm{Ni}$ lies at a slightly higher substrate temperature than for Co. There is also a difference in affinity to oxygen, although the difference between $\mathrm{Co}$ and $\mathrm{Ni}$ is even smaller than between $\mathrm{Co}$ and $\mathrm{Fe}$ [20]. The columnar inclinations found therefore resemble those of Co ([30], $\left.60^{\circ} 4 \mathrm{mPa}, 90-370 \mathrm{~K}, 4 \mathrm{~nm} \mathrm{~s}^{-1}\right]$ but care should be taken since only two films were investigated. Bundling has been observed to have a maximum at $200 \mathrm{~K}$ and disappear above $310 \mathrm{~K}$. At $123 \mathrm{~K}$, the texture is two degree $[111](1 \overline{1} 0)$ with the $a$ texture inclination of $50^{\circ}$. At $343 \mathrm{~K}$, the degree of orientation is almost zero.

That the difference between $\mathrm{Co}$ and $\mathrm{Ni}$ can be quite big was shown by Hara et al. in 1991 [58]. He discusses CoNi alloy films prepared at an incidence angle of $60^{\circ}$, substrate temperature of $213 \mathrm{~K}$, rate of $6 \mathrm{~nm} \mathrm{~s}^{-1}$ and a pressure of 4 $\mathrm{mPa}$. At a $\mathrm{Ni}$ content of $0 \%$ and $20 \%$, the columnar inclination was $30^{\circ}$; whereas at a $\mathrm{Ni}$ content of $65 \%$, the columnar inclination has changed to $47^{\circ}$. This is reflected in the bundling which decreased with increasing $\mathrm{Ni}$ content down to a minimum at $65 \% \mathrm{Ni}$. The degree of orientation exactly followed this behaviour. Since pure Co is hexagonal and pure $\mathrm{Ni}$ is cubic, the texture also changes with composition. Below $30 \% \mathrm{Ni}$, the texture is hexagonal; at $40 \%$, the [111] and [0002] orientations coexist; and at $95 \% \mathrm{Ni}$, the texture is cubic. Both the [0001] and the [111] axis are inclined $50^{\circ}$ from the substrate normal.

If Hara's model is correct, then one must conclude from these data that the surface diffusion increases with increasing $\mathrm{Ni}$ content up to $65 \%$ and then slightly decreases again. If this is caused by a difference in $\mathrm{H}_{2} \mathrm{O}$ contamination, the minimum bundling should be found for pure $\mathrm{Ni}$, not at $65 \%$. The close correlation between the degree of orientation suggests a possible influence of texture formation on surface diffusion. This influence could be either direct, as suggested by Hara et al. [48], or through contamination. Sachtler [47] proved that the adsorption energy of gasses on metals differs for different crystal planes. One should therefore regard the possibility of a change in $\mathrm{H}_{2} \mathrm{O}$ contamination with texture. This might also explain why the van der Drift model does not seem to predict the correct texture inclinations.

\section{Conclusion}

Of the models presented in literature that relate process parameters to columnar inclination, Hara's model is the only one that correctly predicts the relation between surface diffusion and columnar inclination and takes conservation of parallel momentum into account. In view of the experiments of van de Waterbeemd and Oosterhout [Fig. 6], the authors believe that this model should be preferred over the other models, although there seem to be a number of arguments against it. Hara's model is based on the assumption that an increase in surface diffusion will make the columns grow toward the vapour incidence direction. This assumption is in contradiction with the intuitive argument that if the surface diffusion becomes very large the adatoms "forget" were they came from and the difference between oblique incidence and normal incidence disappears. Also, molecular dynamics simulations do not seem to support the assumed effect of parallel momentum on surface diffusion. Whether or not Hara's model is correct, in first approximation, an increase in surface diffusion should either increase or decrease the columnar inclination. Experiments, of which only a small number are listed in Section 4, clearly support the Hara model. However, the authors want to stress that this model might be right for the wrong reason.

Bundling of the columns can be simply explained from geometrical considerations. Therefore, it is unnecessary to use the conservation of parallel momentum to explain bundling.

Surface diffusion plays a key role in columnar growth. Contamination with residual gasses is at least as important as the film temperature. Depending on film temperature, contamination has either an increasing or decreasing effect on the surface diffusion. The mean diffusion distance could be calculated if the partial pressures and desorption energies of the background gasses were known. These data are very hard to obtain so exact calculations cannot be made. It is only possible to indicate trends.

Comparing surface diffusion calculations with published measurements on the columnar inclination in $\mathrm{Fe}, \mathrm{Co}$ and $\mathrm{Ni}$ leads to the conclusion that Hara's model can be applied if the film temperature is about $100 \mathrm{~K}$ higher than the measured temperature. It is likely that the temperature of the substrate holder was measured in the experiments. If the contact between the substrate and the substrate holder is poor, this could explain the difference in temperature. Another possibility is that energy needed for hopping of the adatoms and the desorption energy of the contaminants are all overestimated.

The experiments seem to indicate that $\mathrm{H}_{2} \mathrm{O}$ contamination increases surface diffusion whereas $\mathrm{O}_{2}$ contamination decreases surface diffusion. The role of $\mathrm{N}_{2}$ and other background gasses is unclear. It seems as if $\mathrm{N}_{2}$ reduced the surface diffusion on $\mathrm{Fe}$ and increases the surface diffusion on $\mathrm{Co}$. The desorption energy of the background 
gasses seems to be dependent on the type of crystal face. The texture orientation of obliquely deposited films is very dependent on surface diffusion and contamination. Models found in literature do not seem to correlate with experiments. The role of contamination is probably underestimated.

\section{Acknowledgements}

The authors wish to acknowledge Dr. Vladimir Kambersky of the Institute of Physics in Prague and Prof. Dr. Bene Poelsema of the University of Twente for fruitful discussions. This work has been supported by the CAMST project and Philips Research.

\section{References}

[1] T.G. Knorr and R.W. Hoffmann, Physical Review 113 (1959), pp. 1039-1046, from: K. Okamoto, T. Hashimoto, K. Hara and E. Tatsumoto, Origin of magnetic anisotropy of iron films evaporated at oblique incidence, Journal of the Physical Society of Japan, 31 (5) (1972) 1374-1379.

[2] D.O. Smith, Anisotropy in permalloy films, J. Appl. Phys. 30 (4) (1959) 264S-265S.

[3] D.O. Smith, M.S. Cohen, G.P. Weiss, Oblique-incidence anisotropy in evaporated permalloy films, J. Appl. Phys. 31 (10) (1960) 17551762.

[4] H. Konig, G. Helwig, Über die struktur schräg aufgedampfter schichten und ihr einfluß auf die entwicklung submikroskopischer oberflächenrauhigkeiten, Optik 6 (2) (1950) 111-125.

[5] P. ten Berge, L. Abelmann, J.C. Lodder, A. Schrader, S. Luitjens, Oblique evaporation of $\mathrm{Co}_{80} \mathrm{Ni}_{20}$ Part II: Continously varying angle of vapour incidence, Journal of the Magnetic Society of Japan 18 (1994) $295-298$.

[6] L. Abeimann, P. ten Berge, J.C. Lodder, Th.J.A. Popma, Oblique evaporation of $\mathrm{Co}_{80} \mathrm{Ni}_{20}$ Part I: Fixed angle of vapour incidence, Journal of the Magnetic Society of Japan 18 (1994) 291-294.

[7] K. Hara, Anomalous magnetic anisotropy of thin films evaporated at oblique incidence, J. Sci. Hiroshima Univ., Ser. A-II (1970), No, 34, pp. 139-163.

[8] L. Abelmann, Oblique evaporation of $\mathrm{Co}_{80} \mathrm{Ni}_{20}$ films for magnetic recording, University of Twente, 1994. (ISBN 90-9007098-2)

[9] M. Kamiya, K. Hara, K. Itoh, K. Okamoto, T. Hashimoto, H. Fujiwara, Magnetic analysis of the stress in nickel films obliquely deposited by sputtering, J. Magn. Magn. Mater. 117 (1992) 232-238.

[10] M. Kamiya, K. Hara, T. Hashimoto, K. Okamoto, H. Fujiwara, A study of crystallites in obliquely deposited iron films by ellipsometry, J. Phys. Soc. Jpn. 52 (10) (1983) 3585-3591.

[11] M. Suzuki, Y. Taga, Anisotropy in the optical absorbtion of $\mathrm{Ag}-\mathrm{SiO}_{2}$ thin films with oblique columnar structures, J, Appl. Phys. 71 (6) (1992) 2848-2854.

[12] A.G. Dirks, H.J. Leamy, Columnar microstructure in yapour-deposited thin films, Thin Solid Films 47 (1977) 219-233.

[13] J.M. Nieuwenhuizen, H.B. Haanstra, Philips Technical Review 27 (1966) 87, from: [Dirks 77].

[14] H.J. Leamy, G.H. Gilmer and A.G. Dirks, The microstructure of vapour deposited thin films, Ch. 4 of: E. Kaldis, Current topics in materials science, Vol. 6, North-Holland, 1980, pp. 309-344,

[15] P. Meakin, Ballistic deposition into inclined surfaces, Phys, Rey. A38 (1988) 994-1004.

[16] J. Krug, P. Meakin, Columnar growth in oblique incidence ballistic deposition-faceting, noise reduction and mean field theory, Phys. Rev. A43 (2) (1991) 900-919.

[17] D. Henderson, M.H. Brodsky, P. Chaudhari, Simulation of structural anisotropy and void formation in amorphous thin films, Appl. Phys. Lett. 25 (11) (1974) 641-643.

[18] S. Müller-Pfeiffer, H, van Kranenburg, J.C. Lodder, A 2-dimensional Monte-Carlo model for thin film growth by oblique evaporation-simulation of 2-component systems for the example of $\mathrm{Co}-\mathrm{Cr}$, Thin Solid Films 213 (1992) 143-153.

[19] Herma yan Kranenburg, Obliquely co-evaporated thin films for magnetic recording thesis, University of Twente, 1992.

[20] J.G.W. van de Waterbeemd, G.W. Oosterhout, Effect of the mobility of metal atoms on the structure of thin films deposited at oblique incidence, Philips Res. Rep. 22 (1967) 375-387.

[21] J.E. Lennard-Jones, The interaction of atoms and molecules with solid surfaces XI: The dispersal of energy from an activated link, Proceedings of the Society of London A163 (1937) 127-131.

[22] 3.E. Lennard-Jones, The migration and aggregation of atoms on solid surfaces, Proceedings of the Physical Society 49E (1937) 140-150.

[23] V. Kamberský, Z. Malek, Z. Frait, M. Ondris, The dependence of the unaxial magnetic anisotropy in evaporated film on the angle of incidence, Czech. J, Phys, B11 (1961) 171-178.

[24] K. Hara, M. Kamiya, T. Hashimoto, K. Okamoto, H. Fujiwara, Oblique-incidence anisotropy of the iron films evaporated at low substrate temperature, J, Magn. Magn. Mater. 73 (1988) 161-166.

[25] S. Lichter, J. Chen, Model for columnar microstructure of thin solid films, Phys. Rev. Lett. 56 (13) (1986) 1396-1399.

[26] J.B. Bindell, T.C. Tisone, Step coverage from an extended sputtering source, Thin Solid Films 23 (1974) 31-47.

[27] G.S. Bales, A. Zangwill, Macroscopic model for columnar growth of amorphous films by sputter deposition, J. Vac. Sci. Technol. A9 (1) (1991) $145-149$.

[28] H.J. Leamy, A.G. Dirks, The microstructure of amorphous rareearth/transition-metal thin films, J. Phys. D10 (1977) L95-L98.

[29] H. Fujiwara, K. Hara, M. Kamiya, T. Hashimoto, K. Okamoto, Columnar growth in evaporated iron films, J. Magn. Magn. Mater. 35 (1983) 296-298.

[30] K. Hara, K. Itoh, M. Kamiya, H. Fujiwara, K. Okamoto, T. Hashimoto, Measurement of magnetoresistance effect in nickel films deposited obliquely by thermal evaporation, J. Magn. Magn. Mater. 92 (1) (1990) 68-72.

[31] M. Volmer, Kristallbildung durch gerichtete Dampfmoleküle, Z. Phys. 5 (1921) 31-34.

[32] A. van der Drift, Evolutionary selection, a principle governing growth orientation in vapour-deposited layers, Philips Res. Rep. 22 (1967) 267-288.

[33] K. Okamoto, T. Hashimoto, K. Hara, M. Kamiya, H. Fujiwara, Columnar structure and texture of iron films prepared at various evaporation rates, Thin Solid Films 147 (1987) 299-311.

[34] E. Bauer, Growth of oriented films on amorphous surfaces, in: M.H. Francombe and H. Sato (Eds.), Single Crystal Films, Pergamon, Oxford, 1964 . pp. 43-65.

[35] R. Hergt, H. Pfeiffer, On the texture formation in metallic films, Phys. Status Solidi A92 (1985) K89-K92.

[36] W.F. Egelhoff Jr., I. Jacob, Reflection High-Energy Electron Diffraction (RHEED) oscillations at $77 \mathrm{~K}$, Phys. Rev. Lett. 62 (8) (1989) 921-924.

[37] J.W. Evans, Factors mediating smoothness in epitaxial thin-film growth, Phys. Rev. B43 (5) (1991) 3897-3905.

[38] D.E. Sanders, D.M. Halstaed, A.E. DePristo, Metal/metal homoepitaxy on fcc (111) and fcc (001) surfaces: Deposition and scattering from small islands, J. Vac. Sci. Technol. A10 (4) (1992) 1986-1992.

[39] Robert C. Weast, Melvin J. Astle, William H. Beyer, CRC Handbook of Chemistry and Physics, CRC Press, Boca Raton, FL, 1985.

[40] A. Roth, Vacuum Technology, North-Holland, Amsterdam, New York, Oxford, 1976. 
[41] C.M. Gilmore, J.A. Sprague, A molecular dynamics study of transient processes during deposition on (001) metal surfaces, J. Vac. Sci. Technol. A13 (3) (1995) 1160-1164.

[42] R. Glang, Vacuum Evaporation, in: L.I. Maissel and R. Glang (Eds.), Handbook of Thin Film Technology, McGraw-Hill, New York, 1970 .

[43] R.E. Honig, RCA Rev. 23 (1962) 567, from: [Glang 70, p. 1.123]

[44] C.A. Neugebauer, Condensation, Nucleation and Growth of Thin Films, in: L.I. Maissel and R. Glang (Eds.), Handbook of Thin Film Technology, McGraw-Hill, New York, 1970.

[45] G. Ehrlich, Molecular Processes at the gas-solid interface, in: C.A. Neugebauer, J.B. Newkirk and D.A. Vermilyea (Eds.), Structure and Properties of Thin Films, Wiley, New York, London, pp. 423-475.

[46] B. Lewis, G.J. Rees, Philos. Mag. 29 (1974) 1253-1280.

[47] W.M.H. Sachtler, Sorption on metals, Transactions 3rd International Vacuum Congress 1 (1965) 41-50.

[48] K. Hara, M. Kamiya, T. Hashimoto, K. Okamoto, H. Fujiwara, Columnar structure of obliquely deposited iron films prepared at low substrate temperatures, Thin Solid Films 158 (1988) 239-244.

[49] K. Okamoto, T. Hashimoto, K. Hara, M. Kamiya, H. Fujiwara, Columnar structure and texture of iron films prepared at various pressures, Thin Solid Films 129 (1985) 299-307.

[50] T. Hashimoto, K. Okamoto, K. Hara, M. Kamiya, H. Fujiwara, Columnar structure and texture of iron films evaporated at oblique incidence, Thin Solid Films 91 (1982) 145-154.

[51] K. Okamoto, T. Hashimoto, H. Fujiwara, K. Hara, M. Kamiya, Magnetic investigation of the columnar grain structure in obliquely deposited iron films, J. Magn. Magn. Mater. 81 (1989) 374-380.
[52] C.R.M. Grovenor, H.T.G. Hentzell, D.A. Smith, The development of grain structure during growth of metallic films, Acta Metallica 32 (5) (1984) $7773-7781$.

[53] T. Hashimoto, K. Okamoto, H. Fujiwara, K. Itoh, K. Hara, M. Kamiya, Columnar structure of obliquely deposited cobalt films prepared at low substrate temperatures, Thin Solid Films 192 (2) (1990) 335-342.

[54] K. Okamoto, K. Itoh, T. Hashimoto, Estimation of magnetocrystalline anisotropy of cobalt films deposited at oblique incidence, $\mathrm{J}$. Magn. Magn. Mater. 87 (3) (1990) 379-386.

[55] K. Hara, T. Kamimori, H. Fujiwara, Texture and columnar structure of evaporated cobalt films: II, Thin Solid Films 66 (1980) 185-189.

[56] H. Fujiwara, K. Hara, T. Kamamori, K. Takemoto, T. Hashimoto, Texture and columnar structure of evaporated cobalt films: I, Thin Solid Films 66 (1980) 177-183.

[57] K. Itoh, K. Hara, M. Kamiya, H. Fujiwara, K. Okamoto, T. Hashimoto, Magnetic analysis of columnar grain structure of obliquely deposited cobait films, J. Magn. Magn. Mater. 94 (1991) 235-241.

[58] K. Hara, K. Itoh, M. Kamiya, K. Okamoto, T. Hashimoto, H. Fujiwara, Magnetic anistropy of oblique vapour-deposited CoNi films, J. Magn. Magn. Mater. 102 (1991) 247-254

[59] D.E. Sanders, A.E. DePristo, Metal/metal homo-epitaxy on fcc (001) surfaces: is there transient mobility of absorbed atoms?, Surf. Sci. 254 (1991) 341-353. 